\title{
Influence of monthly varying vegetation on the simulated climate in Europe
}

\author{
DIANA RECHID* and DANIELA JACOB
}

\author{
Max-Planck-Institute for Meteorology, Hamburg, Germany \\ (Manuscript received October 11, 2004; in revised form July 15, 2005; accepted October 10, 2005)
}

\begin{abstract}
In this study the regional climate model of the German Max-Planck-Institute for Meteorology (REMO) is used to analyse the effect of monthly varying vegetation on the simulated climate in Europe. For this investigation the annual cycle of vegetation is implemented in the land surface parameterization scheme of REMO. As input data source a new global dataset of land surface parameters is used. It contains monthly varying vegetation parameter values for leaf area index, fractional vegetation cover and background surface albedo. This dataset is adapted to both standard REMO model domains at 0.5 degree and 0.16 degree horizontal resolution focusing Europe. For both resolutions present-day climate simulations are performed to examine the sensitivity of REMO to the modified vegetation parameterization. The simulation results are compared to corresponding reference simulations where vegetation parameter values are held constant in time. A validation is done by the comparison of the model results with several gridded observational datasets. A significant influence of monthly varying vegetation on the regional climate can be demonstrated. Vertical surface fluxes, near surface temperature and precipitation are strongly affected. The temporal analysis of the results reveals that the vegetation effect on the simulated climate occurs mainly in the summer season. In general, the simulated near-surface climate becomes cooler and wetter during the growing season. Concerning the spatial resolution, main effects can be detected in eastern Europe and the Hungarian lowlands. In these regions the more realistic vegetation treatment improves the simulated mean annual cycles of $2 \mathrm{~m}$ temperature and precipitation with respect to the observations.
\end{abstract}

\begin{abstract}
Zusammenfassung
In dieser Studie wird mit dem regionalen Klimamodell des Max-Planck-Instituts für Meteorologie (REMO) der Einfluss zeitlich variierender Vegetation auf das simulierte Klima in Europa untersucht. Dazu wird in das Landoberflächenschema des Modells der Jahresgang der Vegetation integriert. Als Datenquelle wird ein neuer globaler Datensatz für Landoberflächenparameter verwendet. Er enthält monatliche Werte der Vegetationsparameter Blattflächenindex, fraktionelle Vegetationsbedeckung und Oberflächenalbedo. Diese globalen Daten werden an die beiden Europa fokussierenden REMO-Standardmodellgebiete mit der horizontalen Auflösung von 0,5 Grad und 0,16 Grad angepasst. Um die Sensitivität des Regionalmodells REMO auf die modifizierte Vegetationsparameterisierung zu untersuchen, werden regionale Klimasimulationen für beide horizontale Auflösungen durchgeführt. Die Simulationsergebnisse werden mit entsprechenden Referenzläufen verglichen, in denen zeitlich konstante Jahresmittelwerte für die Vegetationsparameter verwendet werden. Weiterhin wird eine Validierung mit verschiedenen Beobachtungsdatensätzen vorgenommen. Ein signifikanter Einfluss zeitlich variierender Vegetation auf das regionale Klima kann gezeigt werden. Besonders stark sind die Oberflächenflüsse, die bodennahe Temperatur und der Niederschlag beeinflusst. Die zeitliche Analyse der Simulationsergebnisse zeigt, dass der Vegetationseffekt hauptsächlich im Sommer auftritt. Während der Vegetationsperiode wird das bodennahe Klima kühler und feuchter. Die räumliche Analyse der Ergebnisse zeigt den Haupteffekt zeitlich variabler Vegetation in Osteuropa und der ungarischen Tiefebene. In diesen Regionen werden die simulierten mittleren Jahresgänge der Temperatur und des Niederschlags durch die Einführung der zeitlich variierenden Vegetation im Vergleich zu den Beobachtungsdaten verbessert.
\end{abstract}

\section{Introduction}

Vegetation strongly modifies the earth surface characteristics. They determine the exchange processes of water, energy and momentum between the land surface and the atmosphere. To specify some important processes: The surface albedo influences the short wave radiation budget. Surface roughness changes the wind in the planetary boundary layer. The density of vegeta-

\footnotetext{
*Corresponding author: Diana Rechid, Max-Planck-Institute for Meteorology, Bundesstraße 53, 20146 Hamburg, Germany, e-mail: rechid@dkrz.de
}

tion cover controls transpiration by leaf stomatal conductance and evaporation by interception of water on the skin of the canopy. Evapotranspiration determines the partitioning of the vertical turbulent heat fluxes into latent and sensible heat. They are the main mechanisms to return energy from the surface into the atmosphere and influence convective processes and the boundary layer structure. These surface processes controlled by vegetation properties are responsible for near surface atmospheric conditions, such as surface temperature, near surface humidity and low level cloudiness and provide the appropriate feedback mechanisms 
to other physical processes in the atmosphere. $\mathrm{Nu}$ merous studies demonstrate the importance of land surface characteristics for surface-atmosphere interactions and the relevance of these processes for climate at all scales in space and time (e.g. AVISSAR and Verstraete, 1990; Sellers, 1991; Pielke et al., 1998). Several investigations address the significance of different surface parameters in atmospheric modelling (e.g. SHUKLA and MinTz 1982; MinTZ 1984; Sud et al., 1988; SUd et al., 1990; RownTREe, 1991; Henderson-SEllers, 1993; PIELKE et al., 1997). Sensitivity studies (COLlINS and AVISSAR, 1994; RodRIGUEZ-CAMINO and AVISSAR, 1998) estimate the relative importance of land-surface parameters. The vegetation properties leaf area index (LAI), roughness length and surface albedo turned out to be dominant parameters for climate model simulations.

A number of recent studies analyse the feedback of vegetation variability on the climate system. How land use change can influence the simulated climate is examined for example by BONAN (1997); STOHLGREEN et al. (1998) or CHASE et al. (2000). BounOUA et al. (2000) investigate the sensitivity of climate to changes in vegetation density induced by natural decadal climate variability using a coupled biosphere-atmosphere model. They find that increases in vegetation density result in cooler and moister near-surface climate. In climate models themselves, the temporal variability of vegetation is often not explicitly specified or simulated. Recent efforts to consider the annual cycle of vegetation in a global climate model are done by LAWRENCE and SLINGO (2004a, 2004b). They prescribe the vegetation annual cycle on the basis of satellite estimates of LAI and they adjust some model parameters in several sensitivity studies to strengthen the relationship between evaporation and vegetation state. They find that an annual cycle of vegetation reduces surface temperatures in extratropical regions during both the summer and winter season. Where the magnitude of LAI values is enhanced, precipitation increases. In the study of LU and SHUTTLEWORTH (2002), vegetation phenology is assimilated into the climate version of the regional atmospheric modelling system (ClimRAMS) in the form of LAI estimates derived by the normalized difference vegetation index (NDVI). They conclude that the effect of enhanced heterogeneity dominates over the effect of an reduced magnitude in LAI fields.

In the present study a mean annual cycle of vegetation is prescribed to the regional climate model of the German Max-Planck-Institute for Meteorology (REMO) as temporally varying boundary condition. It is derived from a global dataset of land surface parameters constructed by HAGEMANN et al. (1999) and HAGEMANN (2002), that contains monthly fields of fractional vegetation cover, LAI and background surface albedo, which is the albedo over snow-free land areas. They are adapted to the regional model. The modified model version of REMO enables us to investigate the impact of seasonally varying vegetation on the simulated climate in Europe.

\section{Model description}

\subsection{Basic characteristics}

The regional climate model REMO (JACOB and PODZUN, 1997; JACOB et al., 2001) is based on the "Europamodell", the former numerical weather prediction model of the German Weather Service (MAJEWSKI, 1991). Further development of the model took place at the Max-Planck-Institute for Meteorology, where the physical parameterizations from the global climate model ECHAM4 (ROECKNER et al., 1996) were implemented. The prognostic variables are surface pressure, temperature, horizontal wind components, specific humidity and cloud water. Their calculations are based on the hydrostatic approximation. The model equations are formulated in a rotated spheric coordinate system. The model can be used in the forecast mode or in the climate mode. In the climate mode continuous runs for long time periods up to decades are carried out with updates of the lateral boundaries every 6 hours (JACOB, 2001). The regional model is nested into the driving fields. These lateral boundary conditions are provided by analysis/reanalysis data or by global climate model results. A relaxation scheme according to DAVIES (1976) is used to adjust the prognostic variables prescribed by the boundary fields in a zone of the 8 lateral grid rows. As lower boundary values land surface characteristics, sea surface temperature and sea ice distribution are prescribed during the whole model simulation (for more details about initialization and boundary conditions see SEMMLER et al., 2004). The horizontal discretization is done on the Arakawa-C-grid. The generally used horizontal resolutions are 0.5 degree and 0.16 degree corresponding approximately to $55 \mathrm{~km}$ and $18 \mathrm{~km}$ grid size, respectively. The vertical discretization is done in a hybrid coordinate system (SIMMONS and BURRIDGE, 1981). The time-stepping is leap-frog with semi-implicit correction and Asselin-filter.

\subsection{Land surface parameterizations}

In REMO version 5.0, which is used for the model simulations in the present study, thermal and hydrological processes in the soil are based on parameterization schemes of ECHAM4 (DKRZ, 1993; ROECKNER et al., 1996). Soil temperatures are calculated from diffusion equations solved in five discrete layers with zero heat flux at the bottom (10 $\mathrm{m}$ depth) according to the scheme of WARRILOW et al. (1986). The heat diffusion in the soil depends on heat capacity and thermal conductivity 
of the soil. Soil hydrology is parameterized in three water budget equations for the temporal alteration of water storage in the soil related water reservoirs, namely snow, vegetation and bare soil. The runoff-scheme is based on catchment considerations including sub-grid scale variations of field capacity over inhomogeneous terrain (DÜMENIL and TODINI, 1992). The vertical turbulent surface fluxes are calculated from MONIN-OBUKHOV similarity theory (LOUIS, 1979) with a higher order closure scheme for the transfer coefficients of momentum, heat, moisture and cloud water within and above the planetary boundary layer.

The land surface processes are controlled by physiological vegetation properties. In REMO they are represented by the vegetation parameters leaf area index (LAI, here the ratio of one-sided leaf area to ground area), fractional vegetation cover (here fraction of photosynthetically active vegetation), background surface albedo, surface roughness length due to vegetation, forest ratio and water holding capacity. In the present study, monthly varying fields are introduced to the parameters LAI, fractional vegetation cover and background surface albedo. Water holding capacity (depending on plant rooting depths) and forest ratio (used as a constant stem index) are not or only marginally affected by the annual vegetation cycle. Surface roughness length is kept constant. A possible impact of temporally varying roughness length due to vegetation is planned to be investigated in a further study. We don't expect any significant effects on the simulated climate, because total surface roughness length is dominated by the orographic variance in most regions.

To provide a basis for later discussions of the study results, surface processes related to the modified parameters are now briefly introduced. The background surface albedo is the albedo over snow-free land areas. Over snow and sea, surface albedo is modified by surface conditions during the model integration time. It determines the short-wave radiation budget at the earth surface. The vegetation cover ratio $C_{v}$ is assigned to each surface grid box. It determines the fraction of grid area where vegetation properties take effect on surface exchange processes. The LAI in particular affects interception and evapotranspiration through stomatal conductance. Intercepted water goes into the skin reservoir, which determines the wet skin fraction $C_{l}$ :

$$
C_{l}=\min \left(1, \frac{W_{l}}{W_{l m x}}\right)
$$

with

$$
W_{l m x}=W_{l m a x}\left(\left(1-C_{v}\right)+C_{v} \cdot L A I\right)
$$

$W_{l}$ is the prognostic variable for the skin reservoir content, $W_{l m x}$ is the maximum skin reservoir content and $W_{\text {lmax }}$ is the maximum amount of water that can be held

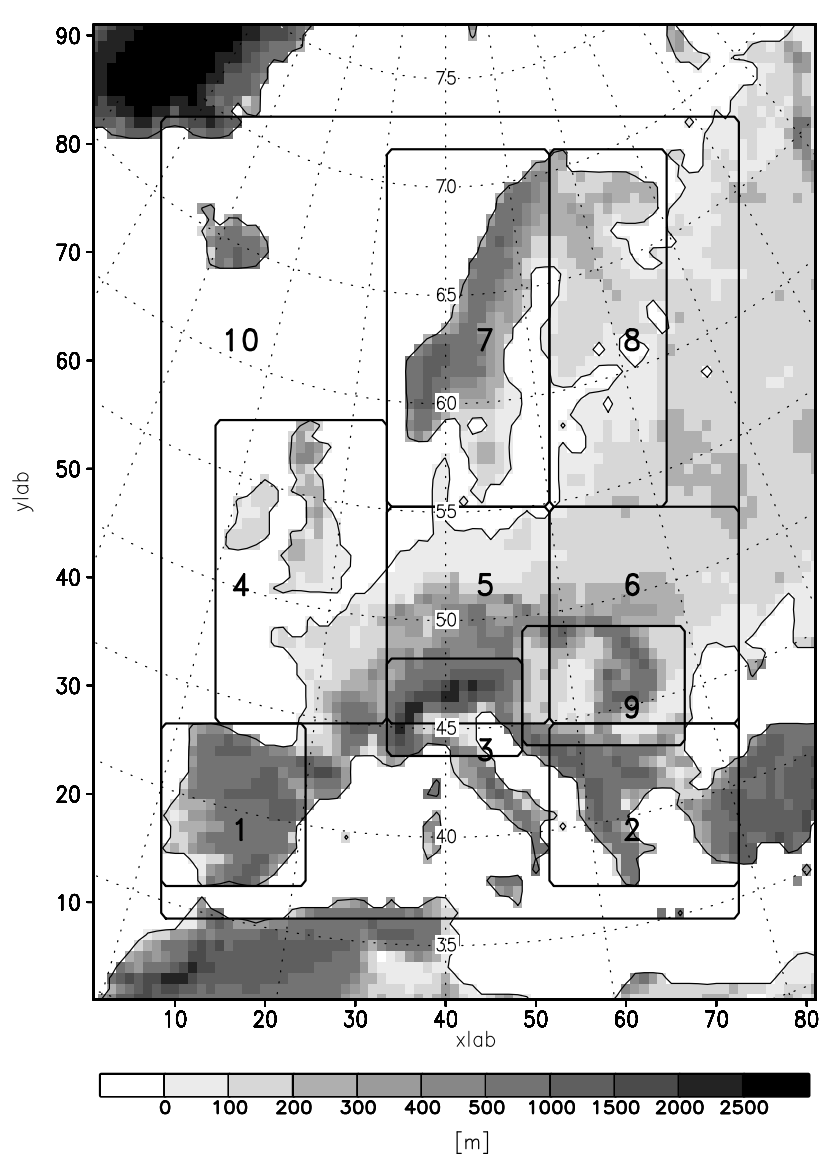

Figure 1: REMO model orography [m] at 0.5 degree resolution with European subdomains: 1 Iberian peninsula, 2 south-eastern Mediterranean, 3 Alpine region, 4 western Europe, 5 central Europe, 6 eastern Europe, 7 western Baltic, 8 eastern Baltic, 9 Hungarian lowlands, 10 model domain area without the 8 boundary grid boxes.

on one layer of leaf or bare ground. It is taken to be 0.2 $\mathrm{mm}$. Evaporation from the skin reservoir $\left(E_{l}\right)$ is at the potential rate:

$$
E_{l}=\rho \cdot C_{h} \cdot\left|v_{h}\right| \cdot\left(q_{v}-q_{s}\right)
$$

$\rho$ is the air density, $C_{h}$ is the transfer coefficient for heat and $v_{h}$ the horizontal velocity. $q_{v}$ is the specific near-surface humidity and $q_{s}$ is the saturation specific humidity at surface temperature and surface pressure. Evaporation from dry vegetated areas is called transpiration. It is proportional to the evaporation efficiency $e$ :

$$
E_{v}=e \cdot \rho \cdot C_{h} \cdot\left|v_{h}\right| \cdot\left(q_{v}-q_{s}\right)
$$

Based on SELLERS et al. (1986), the evaporation efficiency $e$ is expressed as a function of stomatal resistance $R$ :

$$
e=\left(1+C_{h} \cdot\left|v_{h}\right| \cdot R\right)^{-1}
$$

with 

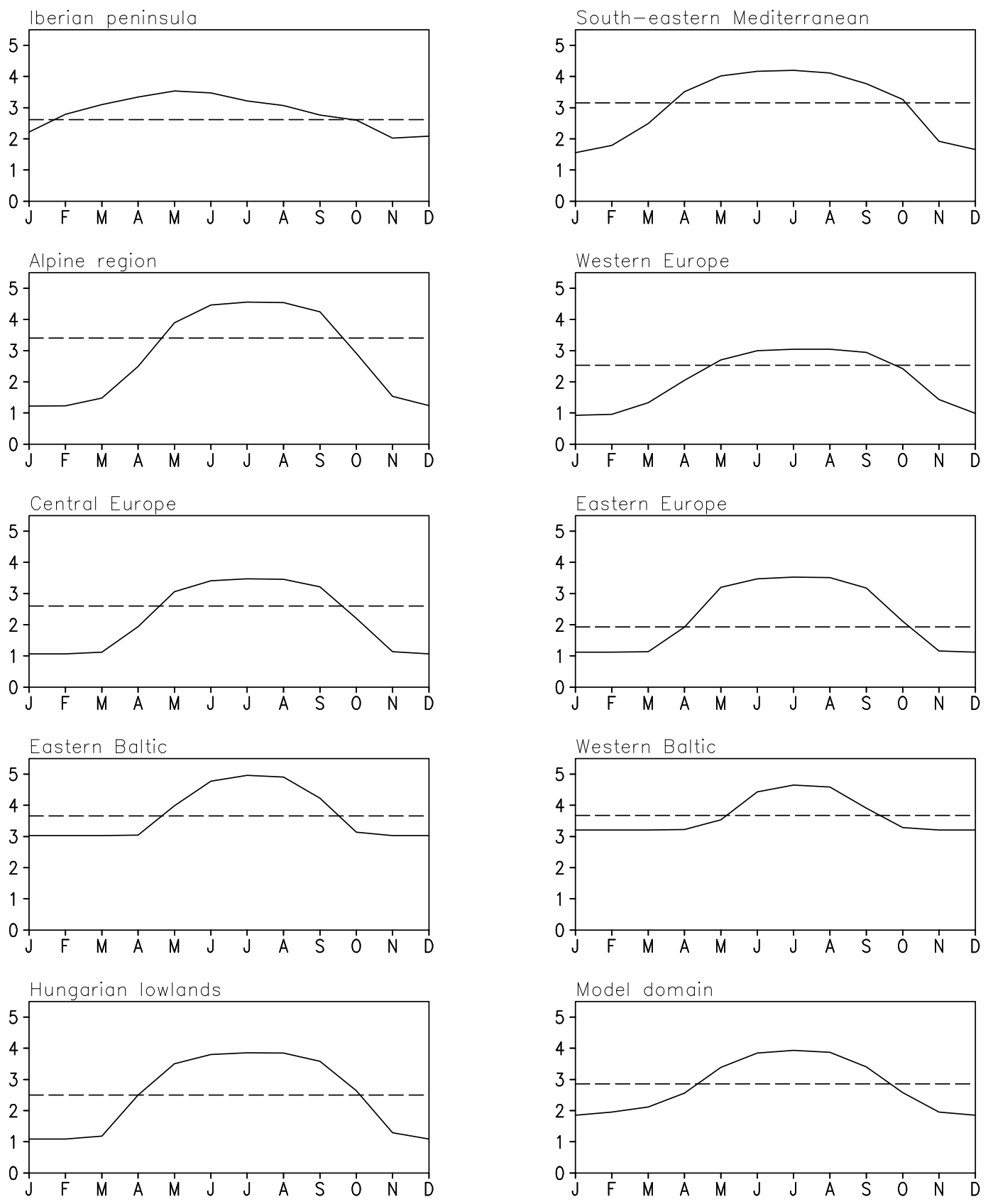

Figure 2: New annual cycle of leaf area index compared to reference constant value area-averaged over the European subdomains.

$$
R=\frac{R_{0}}{F\left(W_{s}\right)}
$$

The water stress factor $F\left(W_{s}\right)$ is an empirical function of the available water in the root zone. $R_{0}$ is the minimum value of the stomatal resistance:

$\frac{1}{R_{0}}=\frac{1}{k \cdot c} \cdot\left(\frac{b}{d \cdot P A R} \cdot \ln \left(\frac{d \cdot e^{k \cdot L A I}+1}{d+1}\right)-\ln \left(\frac{d+e^{-k \cdot L A I}}{d+1}\right)\right)$

\subsection{Study design}

(2.7) plemented in the regional climate model REMO. The

where

vegetation cycle is derived from a global dataset of 

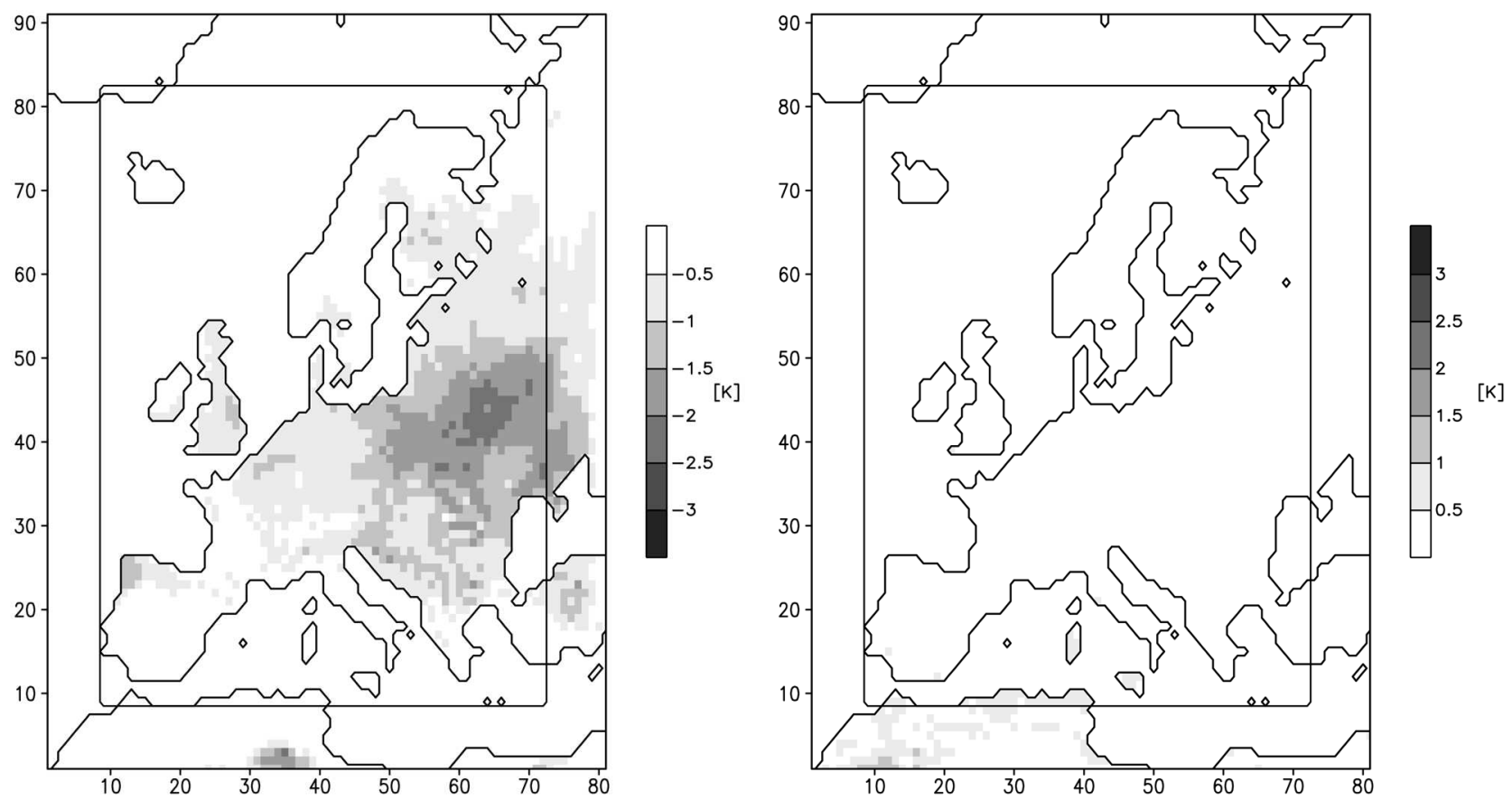

Figure 3: Seasonal mean JJA 1979-1993 of negative (left panel) and positive (right panel) change in surface temperature [K] due to monthly varying vegetation. The difference VEG-0.5 - REF-0.5 is plotted.

land surface parameters (HAGEMANN et al., 1999; Hagemann, 2002). These data fields are based on the global distribution of major ecosystem types according to the definitions given by OLSON (1994a, 1994b). This global dataset of land use classes was derived from Advanced Very High Resolution Radiometer AVHRR data at $1 \mathrm{~km}$ resolution supplied by the International Geosphere-Biosphere Program (EIDENSHINK and FAUNDEEN, 1994) and constructed by the U.S. Geological Survey $\left(1997^{1}, 2002^{2}\right)$. For each land use class parameter values for background surface albedo, fractional vegetation cover, leaf area index, forest ratio, roughness length and soil water holding capacity are allocated. The global datafields are adapted to the 0.5 degree and 0.16 degree standard model domains of REMO focusing on Europe (RECHID, 2001). The monthly vegetation values for fractional vegetation cover, LAI and background surface albedo are estimated by a global data field of the monthly growth factor, which determines the growth characteristics of the vegetation at a horizontal resolution of 0.5 degree (HAGEMANN, 2002). This method enables the preparation of an annual vegetation cycle that remains consistent with all land surface parameter values used in the model. These monthly vegetation fields are prescribed to the model as temporally varying boundary conditions. During the model simula-

\footnotetext{
${ }^{1}$ Global land cover characteristics data base. http:// edcwww.cr.usgs. gov/landdaac/glcc/globe_int.html

${ }^{2}$ Global land cover characteristics data base version 2.0. http://edcdaac.usgs.gov/glcc/globedoc2_0.html
}

tion, the monthly values are interpolated for the $5 \mathrm{~min}$ utes model time step at 0.5 degree horizontal resolution and for the 2 minutes model time step at 0.16 degree resolution.

To investigate the sensitivity of the regional model to the modified vegetation parameterization model simulations for both horizontal resolutions with 20 vertical atmosphere levels are performed. The model run at 0.5 degree resolution (VEG-0.5) simulates 15 years of today's climate (1979-1993) driven by lateral boundary conditions and sea surface temperatures from the European Centre for Medium-Range Weather Forecasts (ECMWF) Reanalysis Project (ERA-15). The 0.16 degree resolution run (VEG-0.16) simulates 5 years (1984-1988) driven by the 0.5 degree run results. The simulation results are compared to corresponding reference runs with temporally constant vegetation input (REF-0.5 and REF-0.16). The evaluation of VEG-0.5 is done for several subdomains representing different European climate regions. The 0.5 degree model domain and the European subdomains superposed on the model orography are presented in Figure 1. For all data analyses only the land area of the different regions is considered. As example the new annual cycle of LAI for all European subdomains in comparison to the former annual mean LAI value is presented in Figure 2. In all European subdomains the LAI shows lower values during winter and higher values during summer in comparison to the former mean LAI values. The largest differences in summer season occur in eastern Europe. The constant annual mean value of the reference simulation is slightly 

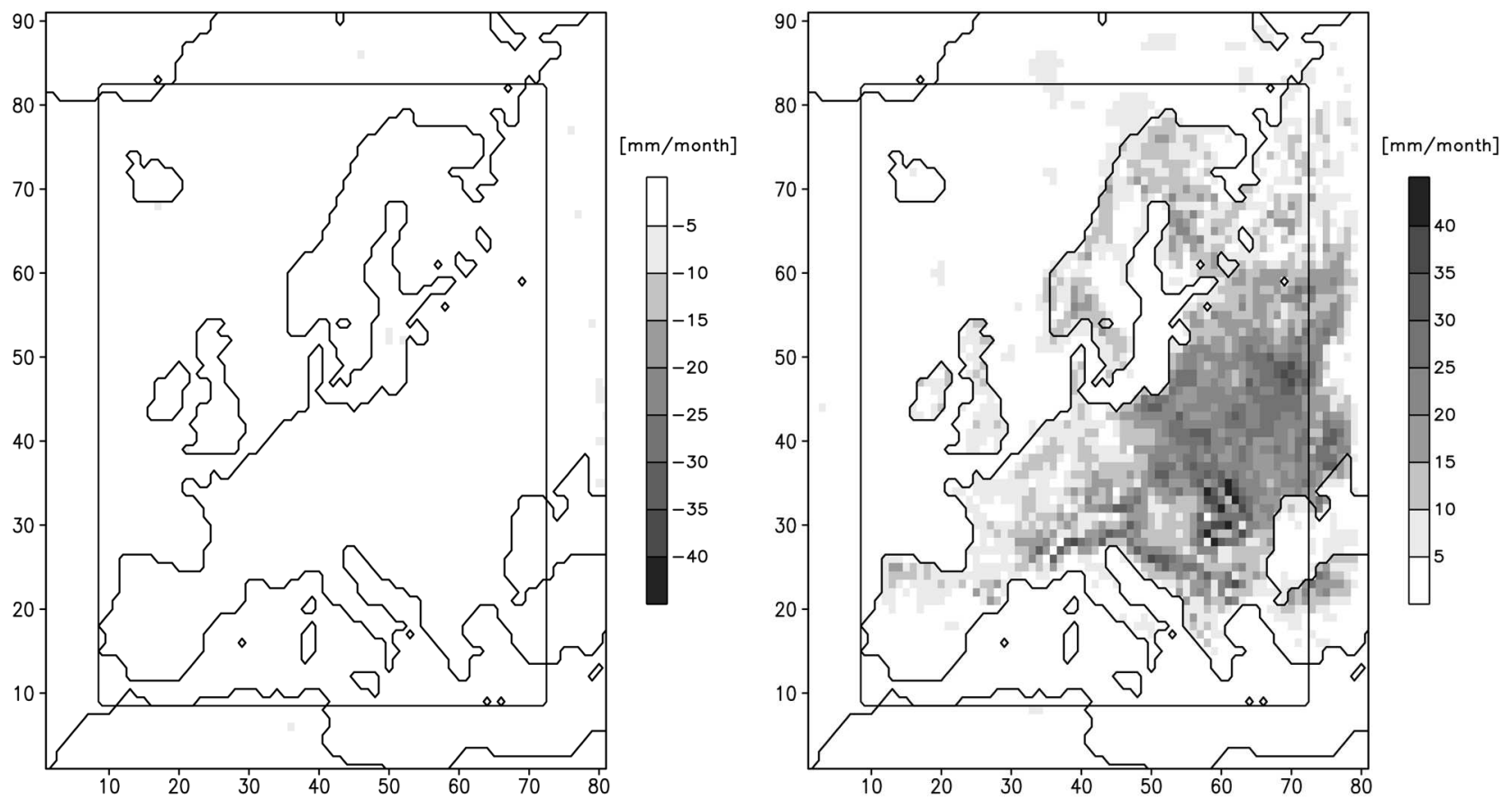

Figure 4: Seasonal mean JJA 1979-1993 of negative (left panel) and positive (right panel) change in precipitation [mm/month] due to monthly varying vegetation. The difference VEG-0.5 - REF-0.5 is plotted.

different from the temporal average of the varying LAI because the minimum and maximum LAI values are corrected for some ecosystem types (HAGEMANN, 2002). But as the annual LAI cycles still exhibit a realistic variation compared to the reference constant annual means with clearly lower values in summer and larger values in winter, the influence on the regional climate can be attributed to the monthly varying vegetation.

\subsection{Results and discussion}

To analyse the simulation results, time series of monthly means are calculated and averaged over the 15 years simulation time period in terms of mean annual cycles and seasonal means. Mean annual cycles are plotted in area-averages calculated for the model domain and the European subdomains introduced in Figure 1. For all investigated regions only land surface area is considered. To examine the influence of resolution some selected results of VEG-0.5 are compared to VEG-0.16 and their respective reference runs.

\subsection{Seasonal means}

During the summer season (June-July-August, JJA) the effect of the annual vegetation cycle reduces the mean surface temperatures in the north-west of Spain, in central and especially in eastern Europe up to $-2 \mathrm{~K}$ (Figure 3). In winter time (December-January-February, DJF) the surface temperature is almost not affected by temporally varying vegetation (not shown). The seasonal means of precipitation are also mostly unaffected in winter time (not shown), but in the summer season a substantial increase in precipitation over the land surface area of the whole model domain can be detected, up to $40 \mathrm{~mm} / \mathrm{month}$ in eastern Europe and the Alps (Figure 4). As in the case of surface temperature and precipitation all investigated parameters respond to temporally varying vegetation mainly during the summer season. In summer vertical exchange processes dominate advective processes. High solar radiation input to the earth surface leads to intensive exchange processes of energy at the land surface which are strongly controlled by land surface characteristics. In contrast, during the winter season low solar radiation input, dominant large-scale weather conditions and snow cover deactivate the control of land surface processes by vegetation properties. Over sea areas there is only a slight change in precipitation. This indicates, that the vegetation effect is mainly restricted to the land area, where the vegetation parameter values are modified. The effect on large-scale atmospheric circulations is marginal. We also analysed the mean sea level pressure and the $850 \mathrm{hPa}$ geopotential (not shown). The new vegetation treatment does not cause any noticeable changes in these parameters. Moreover, the biases compared to the input data from the ECMWF reanalyses are even larger with one order of magnitude in some regions (not shown). Altogether, the new vegetation scheme has no impact on the large scale pressure regimes.

As described in section 2.2 fractional vegetation cover and LAI directly control the evapotranspiration processes. During the summer season increased values of fractional vegetation cover and LAI raise transpi- 

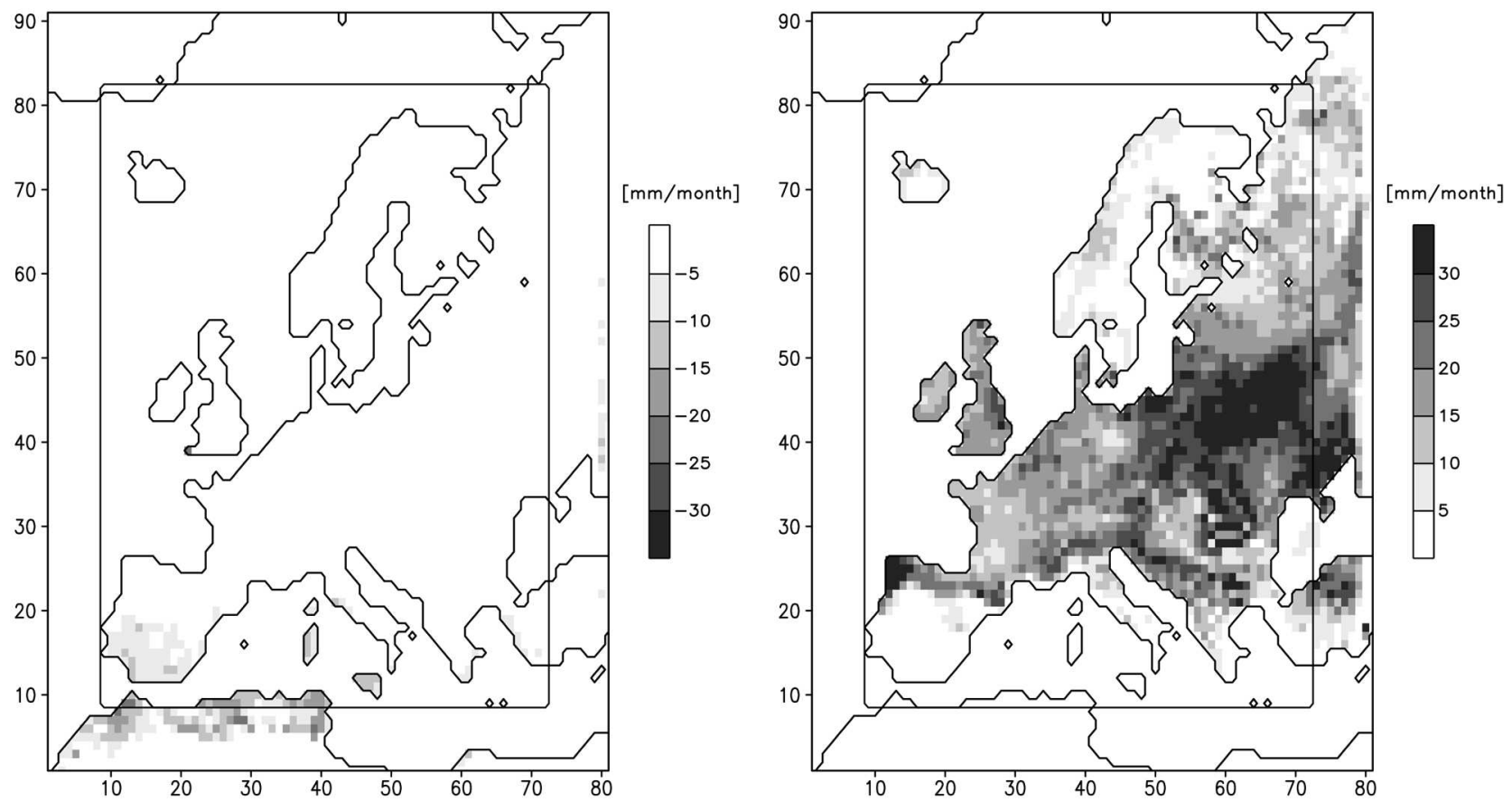

Figure 5: Seasonal mean JJA 1979-1993 of negative (left panel) and positive (right panel) change in evapotranspiration [mm/month] due to monthly varying vegetation. The difference VEG-0.5 - REF-0.5 is plotted.

ration. The simulated surface evapotranspiration (Figure 5) does significantly increase over major parts of the land surface. Strongest changes occur in regions, where the LAI shows significantly higher values compared to reference (Figure 2). Accordingly, the surface latent heat flux is increased over major parts of the European land area whereas the surface sensible heat flux is decreased. Soil wetness is reduced over some parts of Europe up to $25 \%$ (not shown), because more water leaves the soil through transpiration. Together, raised evapotranspiration and latent heat flux decrease surface temperature and the water content in the soil and increase water vapour in the atmosphere and therefore precipitation.

\subsection{Mean annual cycles}

The temporally varying vegetation directly modifies the mean annual cycles of the vertical fluxes of humidity and heat at the surface. Higher LAI values in summer strongly increase evapotranspiration over land (as presented in chapter 4.1 and Figure 5). This raises latent heat fluxes during the summer months up to 30 $\mathrm{W} / \mathrm{m}^{2}$ (not shown). Accordingly, sensible heat fluxes are reduced and surface temperatures decrease. Figure 6 presents the differences in the mean annual cycles of surface temperatures caused by the temporally varying vegetation. Most European regions show lower temperature values during the summer season whereas temperature in winter is only slightly affected. Strongest changes occur in eastern Europe and the Hungarian lowlands with differences up to $-1.7 \mathrm{~K}$ in June. As illustrated in Fig- ure 2 these are the regions with the largest LAI differences in summer. Besides, the continental climate in eastern Europe is characterised by relatively high temperatures and low precipitation in summer. High solar radiation input leads to intensive vertical exchange processes at the earth surface which are determined by the surface properties. Thus, the altered vegetation parameter values strongly influence the simulated climate in this European region. On the Iberian peninsula, the largest differences in surface temperature appear in May. In this region, summer season starts earlier and accordingly, maximum vegetation is already reached in May. In western Europe and the western Baltic area surface temperatures are almost not affected. In the case of western Europe, this can be explained by minor LAI changes in summer (Figure 2). In the western Baltic land area, in contrast, the LAI values are enhanced. But here, the modified vegetation has only slight effects because this area is close to the sea. The annual temperature cycle is less distinctive than in other European regions and the summer magnitude of near-surface temperatures is discernable lower. Evapotranspiration and latent heat fluxes are less affected by vegetation due to the lower saturation deficit of water vapour in the atmosphere. This results in lower temperature differences between VEG-0.5 and REF-0.5. Besides, the strongest effect of the westerly winds on Europe occur on the Norwegian coast. Thus, the western Baltic area is dominated by large scale weather conditions and regional surface characteristics are of secondary importance. 

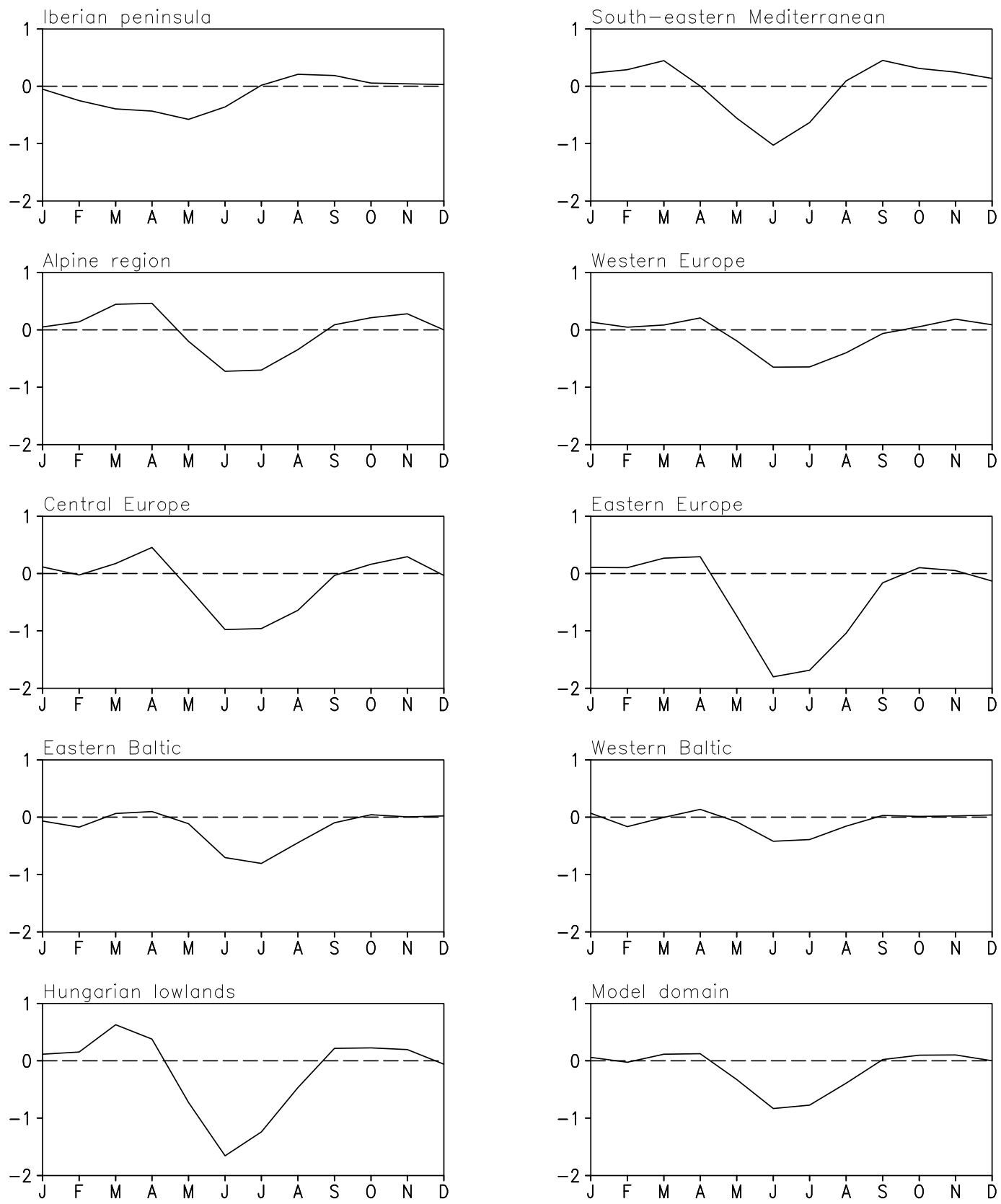

Figure 6: Mean annual cycle 1979-1993 of change in surface temperature [K] due to monthly varying vegetation area-averaged over the European subdomains. The difference VEG-0.5 - REF-0.5 is plotted.

The new vegetation treatment strongly influences the simulated annual precipitation cycle in Europe (Figure 7). In all European subregions precipitation increases during the summer months, whereas winter precipitation is not affected. The strongest effects here also occur in the continental climate zones. In eastern Europe the largest precipitation differences reach up to $+30 \mathrm{~mm}$ in June. In this region with intensive vertical exchange processes at the surface in summer the influence of the annual vegetation cycle becomes most visible. To explain the vertical interactions between soil-vegetationatmosphere several parameters for eastern Europe are composed in Figure 8. In plot 8a and 8b precipitation is separated into large scale precipitation and convective precipitation. It becomes evident that the precipitation change is only caused by the convective part, whereas the large scale precipitation is not influenced. This means, that vegetation properties have local effects on the vertical exchange processes but not on the large scale atmospheric conditions. The higher LAI values in summer increase evapotranspiration up to a difference of $30 \mathrm{~mm}$ in June (8d). More leaves intercept more water on the canopy which can evaporate from there at the potential rate (see also chapter 2.2). Increased evapotran- 

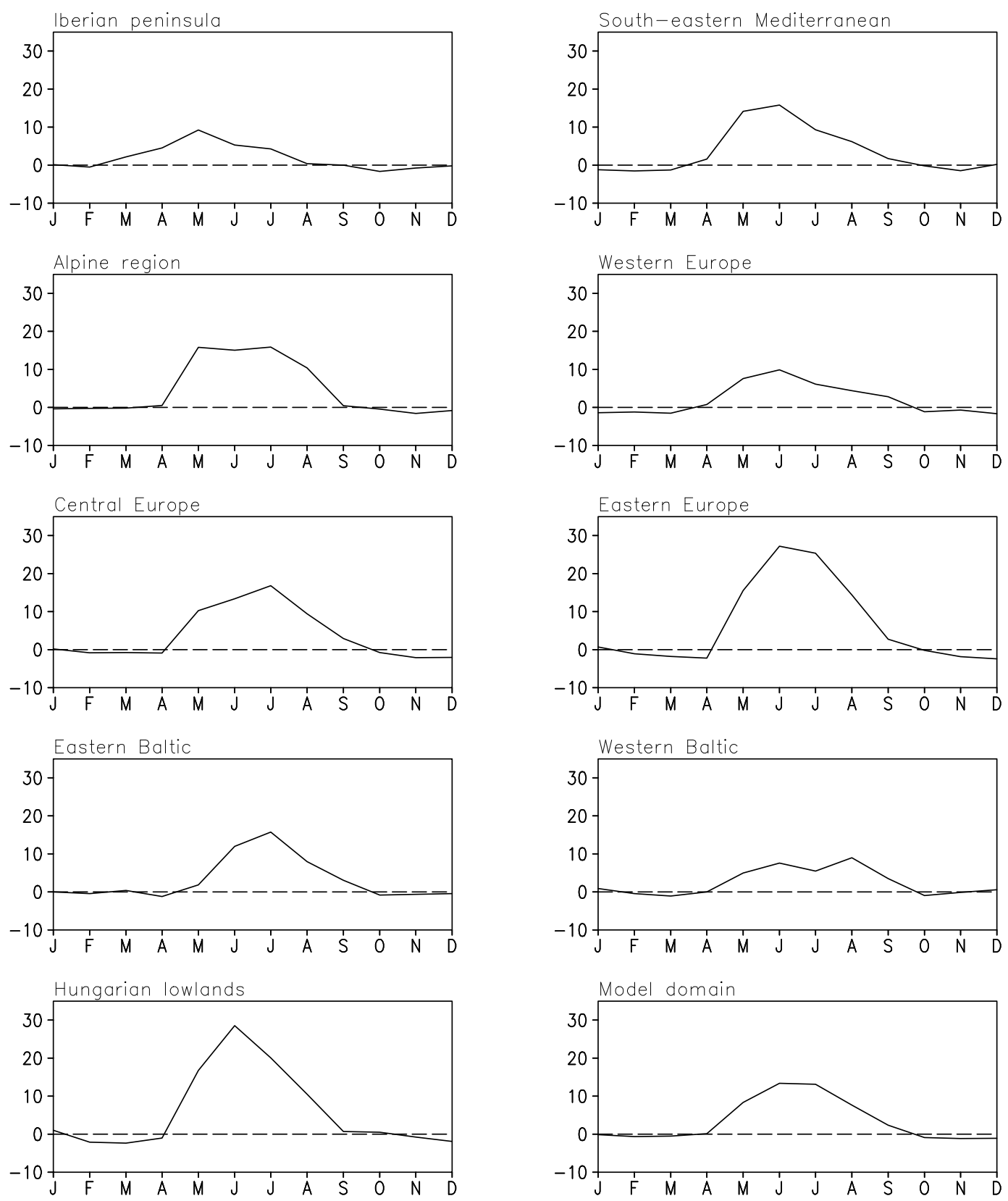

Figure 7: Mean annual cycle 1979-1993 of change in precipitation [mm/month] due to monthly varying vegetation area-averaged over the European subdomains. The difference VEG-0.5 - REF-0.5 is plotted.

spiration raises the latent heat flux by up to $30 \mathrm{~W} / \mathrm{m}^{2}$ (8e). The sensible heat flux decreases by up to $15 \mathrm{~W} / \mathrm{m}^{2}$ (8f). The soil heat flux is also decreased which becomes evident by lower surface temperature $(8 \mathrm{c})$. The surface thermal radiation is reduced by $8 \mathrm{~W} / \mathrm{m}^{2}$ (not shown). Whereas the water flux into the atmosphere is higher, less water is stored in the soil $(8 \mathrm{~g})$. In April after the spring runoff peak the soil water content is filled up almost to the same level as in the reference simulation, but during the following summer months less water reaches the soil due to increased interception and more water leaves the soil through transpiration. The maximum changes in evapotranspiration and precipitation occur in
June. During the following summer months, the soil water in the upper layers is depleted and limits evapotranspiration. The increased water content in the atmosphere does not lead to higher fraction of cloud cover (8h), but is raising precipitation. Altogether, the water storage in the soil is reduced and the hydrological cycle is intensified.

\subsection{Influence of horizontal resolution}

To investigate the influence of the horizontal model resolution to the modified vegetation parameterization a 5 year long REMO simulation at 0.16 degree resolution is 

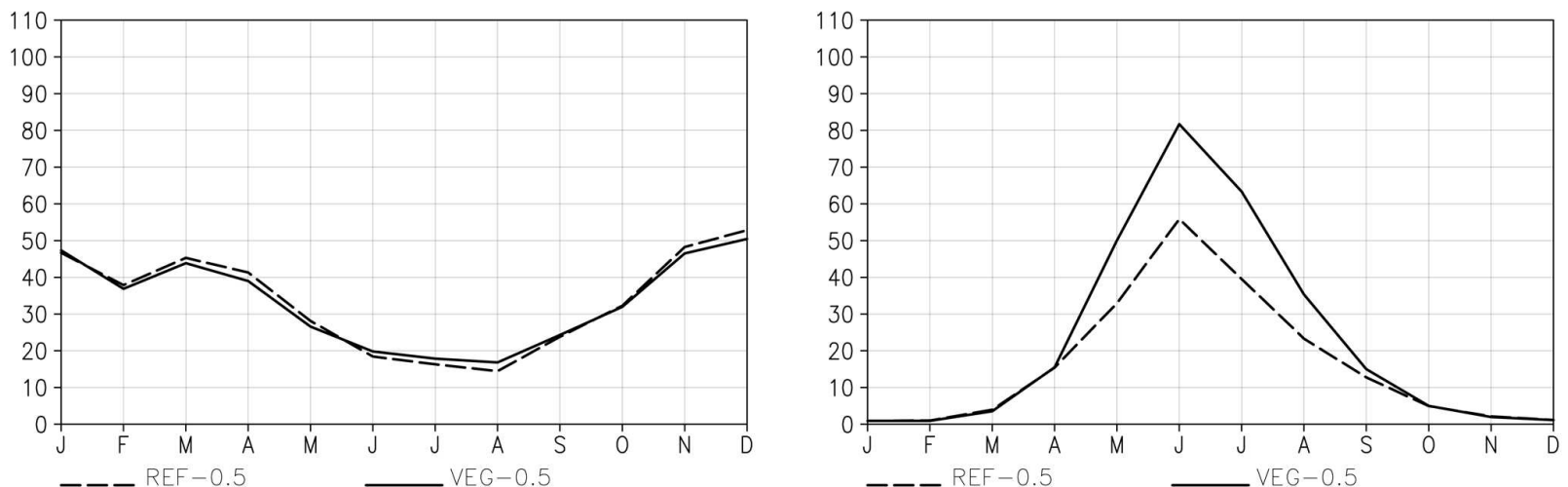

a)

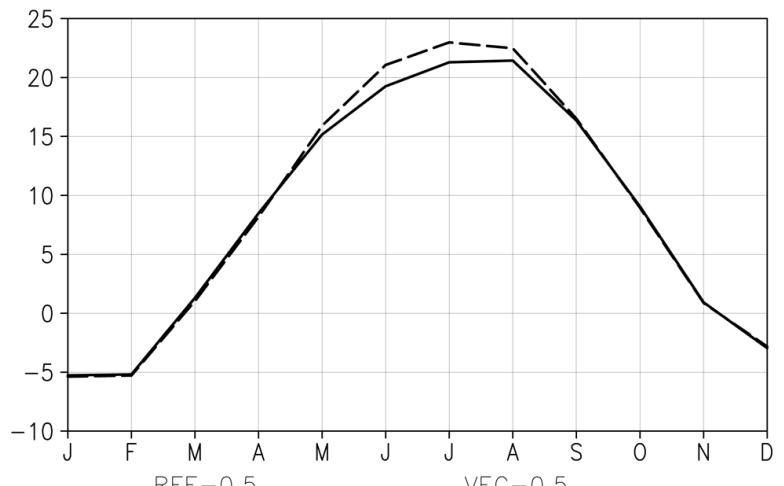

c)

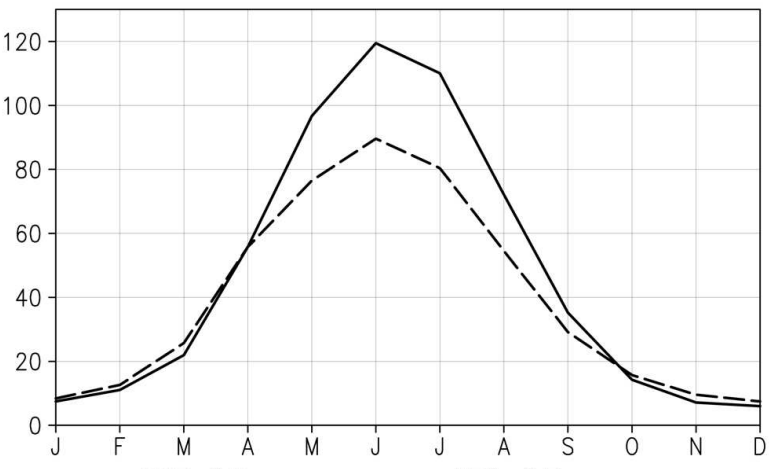

e)

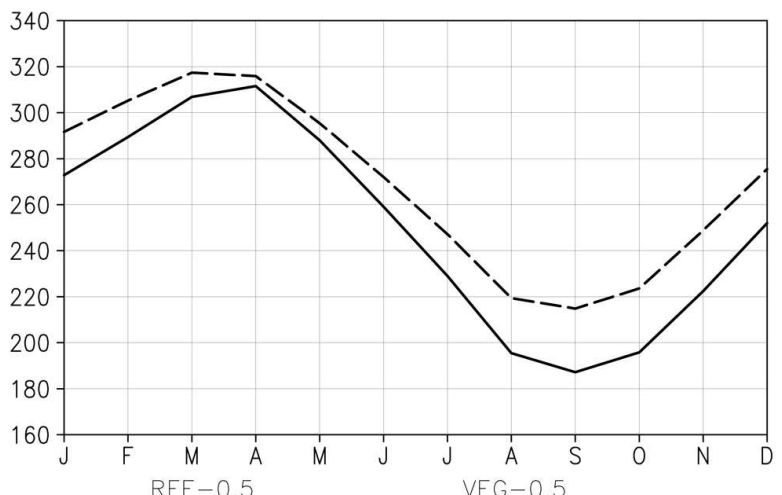

g)

Figure 8: Mean annual cycles 1979-1993 of reference run REF-0.5 and simulation VEG-0.5 area-averaged over eastern Europe: a) large scale precipitation [mm/month], b) convective precipitation [mm/month], c) surface temperature [ C], d) evapotranspiration [mm/ month], e) latent heat flux $\left[\mathrm{W} / \mathrm{m}^{2}\right]$, f) sensible heat flux $\left[\mathrm{W} / \mathrm{m}^{2}\right]$, g) soil wetness $[\mathrm{mm}]$, h) fractional cloud cover $[0,1]$ b)

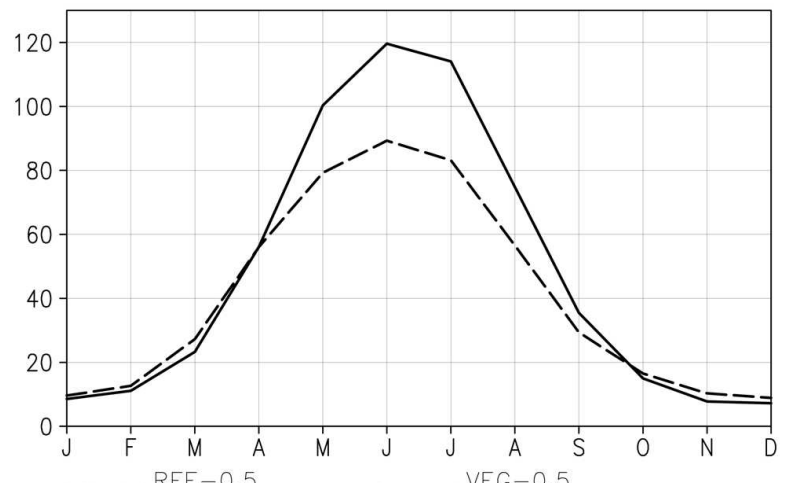

d)

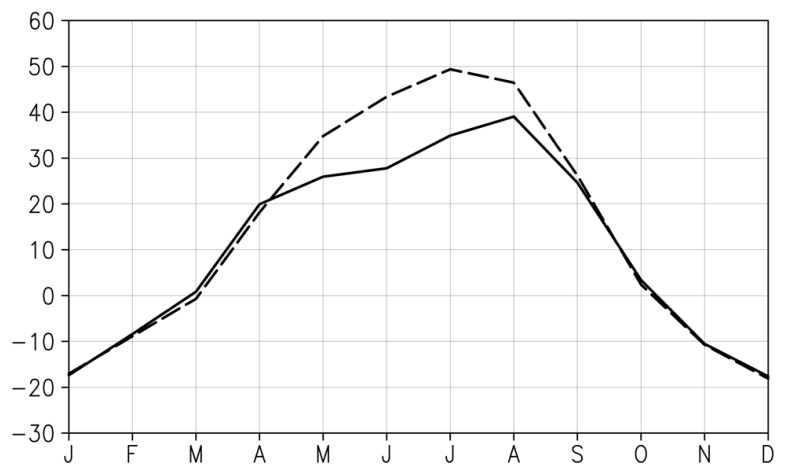

f)

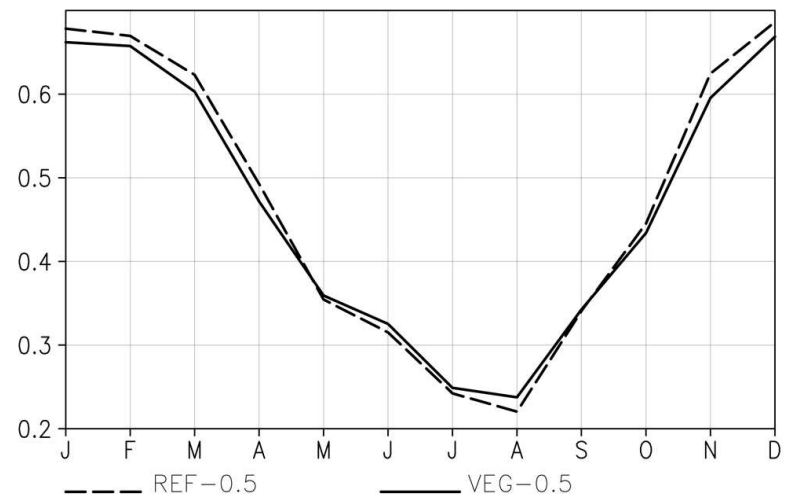

h) 


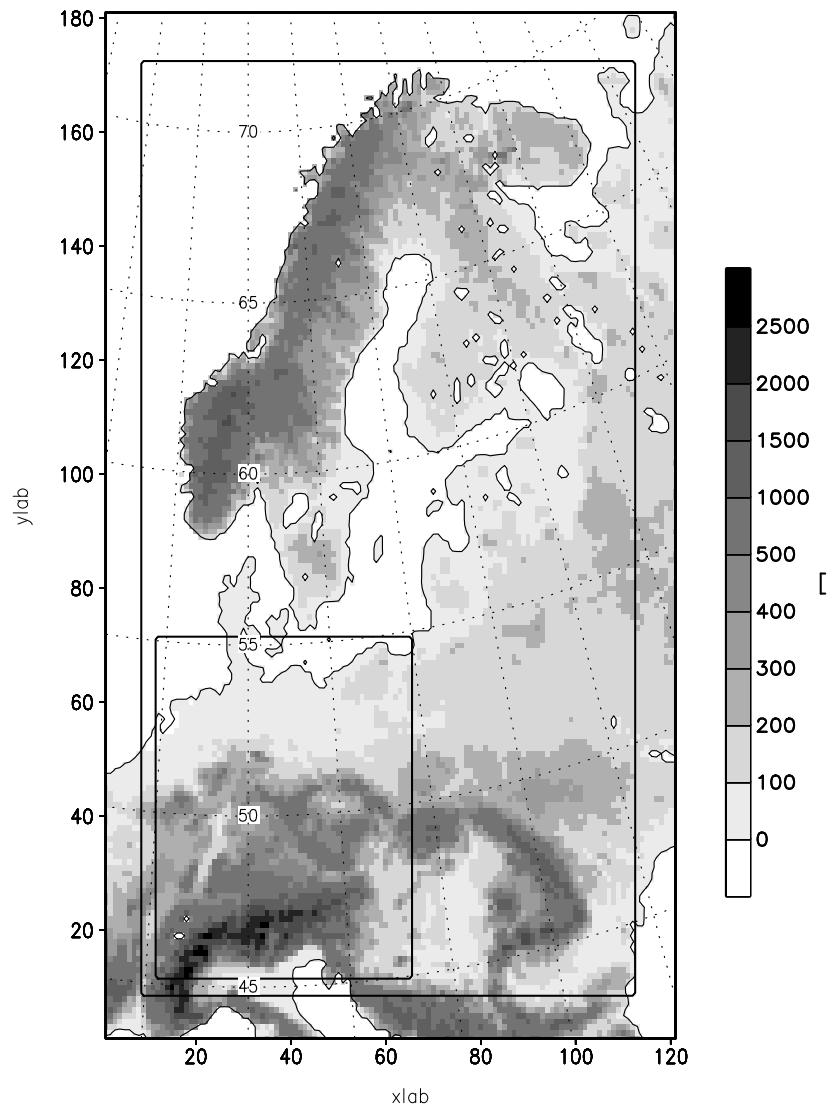

Figure 9: REMO model orography $[\mathrm{m}]$ at 0.16 degree resolution with subdomain central Europe and model domain without boundary zone.

performed. The 0.16 degree model domain superposed on the model orography is presented in Figure 9. To obtain the mean annual cycles of the simulation results time series of monthly means are calculated and averaged over the time period 1984-1988. For the 0.5 degree run the same temporal average for these 5 years is calculated. The subdomain central Europe and the model domain area are chosen exemplarily to compare results of VEG-0.16 and VEG-0.5 in terms of area-averaged annual cycles. The mean annual cycles of temperature and precipitation indicate no significant deviations. In summer, the temperature differences between VEG-0.16 and REF-0.16 are slightly lower than the differences between VEG-0.5 and REF-0.5 (Figure 10). In the study at 0.16 degree resolution, the maximum precipitation change is also slightly lower and in the case of the model domain-average the maximum change in precipitation is reached one month earlier at 0.16 degree resolution (Figure 11). The upper and lower curves in Figure 10 and 11 show the temperature and precipitation changes $+/-$ the standard deviations of the area averages, respectively. In all cases, the spatial variability increases in summer, but without noticeable differences caused by the different horizontal resolutions. Together, the influence of the horizontal model resolution on the areaaveraged mean temperature and precipitation cycles of
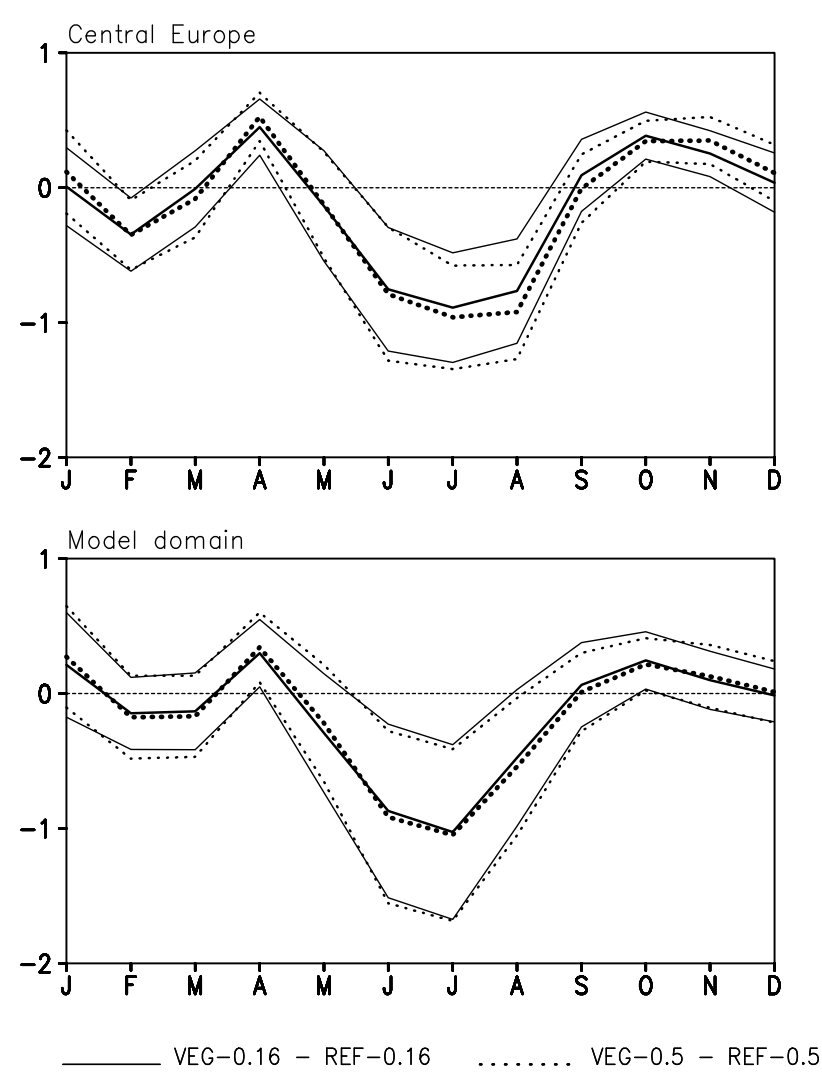

Figure 10: Mean annual cycle 1984-1988 of change in surface temperature $[\mathrm{K}]$ due to monthly varying vegetation area-averaged over central Europe (upper panel) and over the whole model domain (lower panel). The differences between VEG-0.16 and REF-0.16 and between VEG-0.5 and REF-0.5 are plotted. The upper and lower curves show the temperature change $+/$ - the standard deviations of the area averages, respectively.

the European regions is only marginal. But looking at smaller areas, the horizontal resolution in combination with the annual vegetation cycle does affect the simulation results. In Figure 12, the horizontal plots of the precipitation differences between VEG-0.16 and REF-0.16 for July are posed next to the corresponding difference plots of VEG-0.5 and REF-0.5. The comparison shows similar results for central and eastern Europe, in mountainous regions they are more structured at 0.16 degree resolution. In the Alpine region there are several grid points with lower precipitation values in the VEG-0.16 simulation, which do not appear at 0.5 degree resolution. Clear differences caused by horizontal resolution occur in northern Europe. In northern Finland and especially at the Norwegian coast over sea precipitation is decreased in VEG-0.16, which is not the case at 0.5 degree resolution. The positive changes in precipitation are differently distributed on the Scandinavian peninsula and over the Baltic Sea in the simulation at 0.16 degree resolution. In some cases, they seem to be displaced eastward. In Scandinavia, the vegetation effect is superposed by the synoptic scale weather conditions strongly affected by 

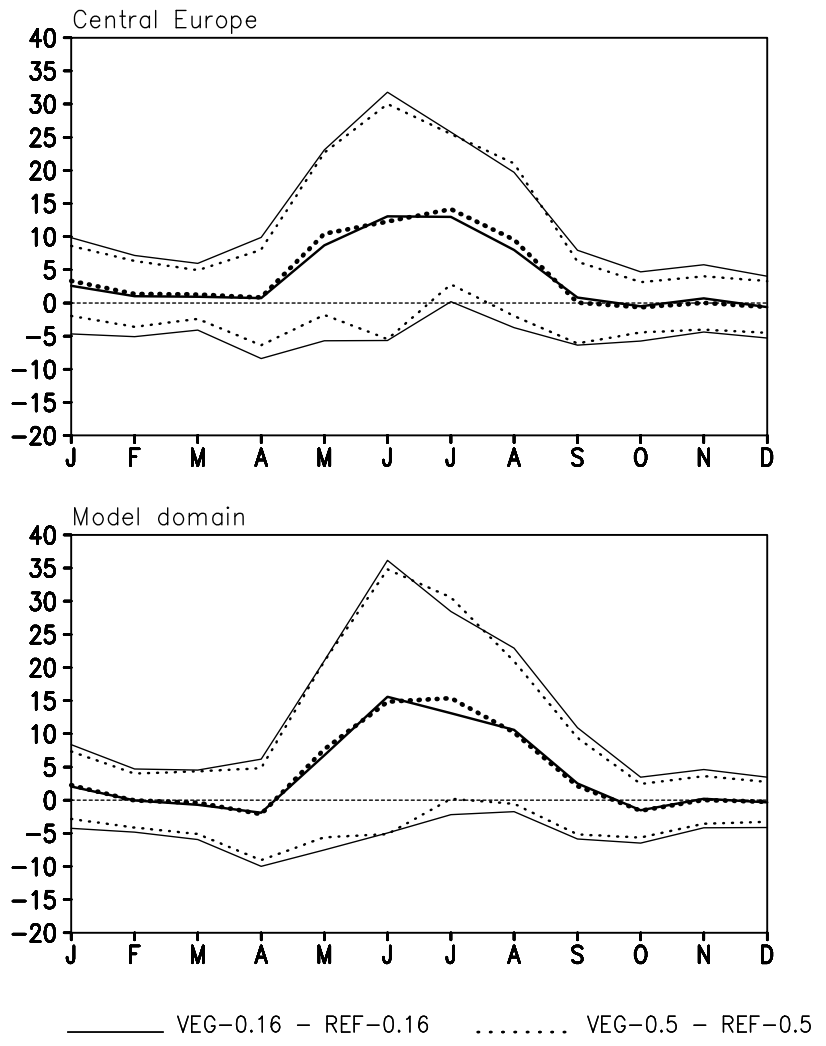

Figure 11: Mean annual cycle 1984-1988 of change in precipitation $[\mathrm{mm} / \mathrm{month}]$ due to monthly varying vegetation area-averaged over central Europe (upper panel) and over the whole model domain (lower panel). The differences between VEG-0.16 and REF-0.16 and between VEG-0.5 and REF-0.5 are plotted. The upper and lower curves show the precipitation change $+/$ - the standard deviations of the area averages, respectively.

the westerly winds. Here, the horizontal model resolution in combination with the modified vegetation treatment leads to changes in the mesoscale atmospheric circulation.

\subsection{Validation}

Observational datasets used for validation purposes are extracted from the Climate Research Unit analyses version 2.0 (CRU, Mitchell et al., 2004, NEW et al., 2000) and the Global Precipitation Climatology Project version 2.0 (GPCP, HUFFMANN et al., 1997).

The CRU dataset provides global $2 \mathrm{~m}$ temperature and precipitation fields in terms of time series of monthly means for the time period 1901-2000 at 0.5 degree horizontal resolution for land surface area. The temperature and precipitation fields are based on gauge measurements. The GPCP precipitation dataset is globally gridded data at 2.5 degree resolution based on gauge measurements over land and satellite data over sea. The GPCP precipitation values are corrected for undercatch of gauge stations. Time series of monthly means are available for 1979-2000. By using area averages we expect to reduce uncertainties in the observations that are caused by location, exposure and altitude of the stations.

Figure 13 presents mean annual cycles of the differences in $2 \mathrm{~m}$ temperature between the simulation results and the CRU observations. For all European subregions the temperature annual cycle is improved due to monthly varying vegetation with respect to the observations. Generally, the simulated annual cycle of 2 $\mathrm{m}$ temperature is characterised by a larger amplitude, but due to the vegetation effect summer temperatures of VEG-0.5 decrease and come to a better agreement with the observations. In eastern Europe temperature values move about $1.5 \mathrm{~K}$ closer to $\mathrm{CRU}$ data.

The validation results for precipitation are presented in Figure 14. The mean annual cycles of precipitation for the simulation results of VEG-0.5 and REF0.5 and the observational data of CRU and GPCP are plotted. Together, the model simulations reproduce the characteristics of the individual precipitation annual cycles in the different European subdomains. However, some noticeable underestimations in precipitation are simulated in the Alpine region in autumn and in the south-eastern Mediterranean in the winter season. In the western Baltic area precipitation is discernably overestimated in spring. During the summer season in central and eastern Europe, the change in precipitation due to temporally varying vegetation causes an overestimation of the maximum precipitation. But regarding the whole annual cycle, the vegetation effect leads to a better agreement with the observations. A clear improvement of the precipitation annual cycle can be detected in the Hungarian lowlands. Here the vegetation effect produces the correct maximum precipitation and an improved annual precipitation cycle. In this region, an artificial summer drying problem is simulated by many climate models (HAGEMANN et al., 2001, SENEVIRATNE et al., 2002). With the more realistic treatment of vegetation the summer drying is reduced, but in late summer and autumn, it remains.

To quantify the validation results presented in Figure 13 and 14, the mean absolute deviations $(d)$ between the model results $(m)$ and the observations $(o)$ are calculated:

$$
\begin{array}{r}
d_{x y}=\frac{1}{n} \sum_{i=1}^{n}\left|m_{x y i}-o_{x y i}\right| \\
d=\frac{\sum_{x y} \cos (\operatorname{lat}(x, y)) \cdot d_{x y}}{\sum_{x y} \cos (\operatorname{lat}(x, y))}
\end{array}
$$

$d_{x y}$ is the mean absolute deviation for the timeseries of monthly means at each grid point. The indices $x$ and $y$ specify the graduating and $n$ gives the month of the annual cycle. To determine the area averages for the European subdomains, the mean absolute deviations are 

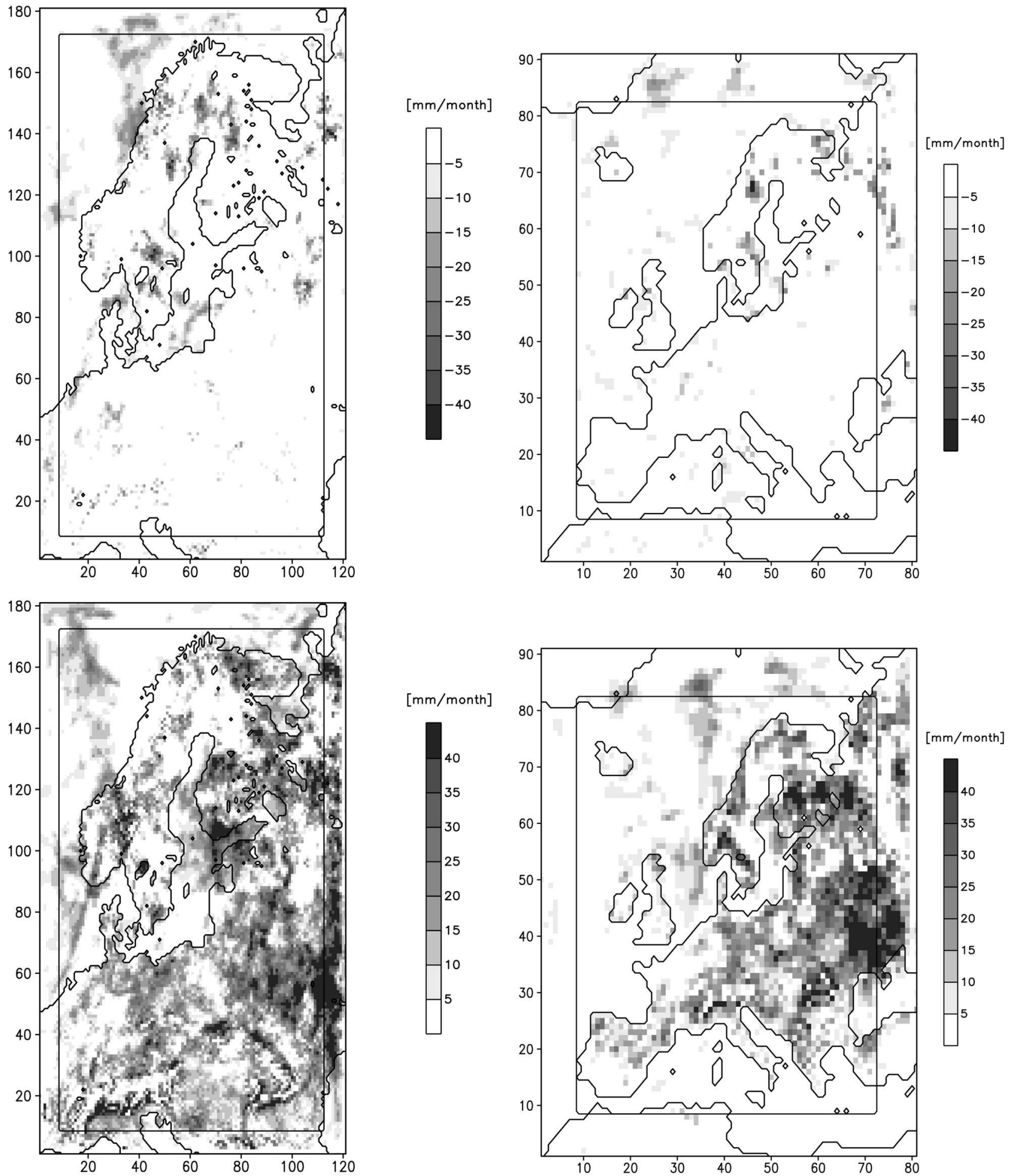

Figure 12: Monthly mean July 1984-1988 of negative (upper panels) and positive (lower panels) change in precipitation [mm/month] due to monthly varying vegetation. The differences VEG-0.16 - REF-0.16 (left panels) and VEG-0.5 - REF-0.5 (right panels) are plotted.

weighted by the cosine of the grid point latitude (lat). The significance of the vegetation effect on the simulation results can be estimated by the standard error $(\Delta d)$ of the mean absolute deviation. The standard error for the timeseries at each grid point $\left(\Delta d_{x y}\right)$ of monthly means is the quotient of standard deviation and square root of the number of time steps. The standard error $\Delta d$ for the area averages over divers grid points is calculated from the error of the timeseries $\Delta d_{x y}$ with error propagation:

$$
\Delta d_{x y}=\sqrt{\frac{1}{n(n-1)} \cdot \sum_{i=1}^{n}\left(\left|m_{x y i}-o_{x y i}\right|-d_{x y}\right)^{2}}
$$



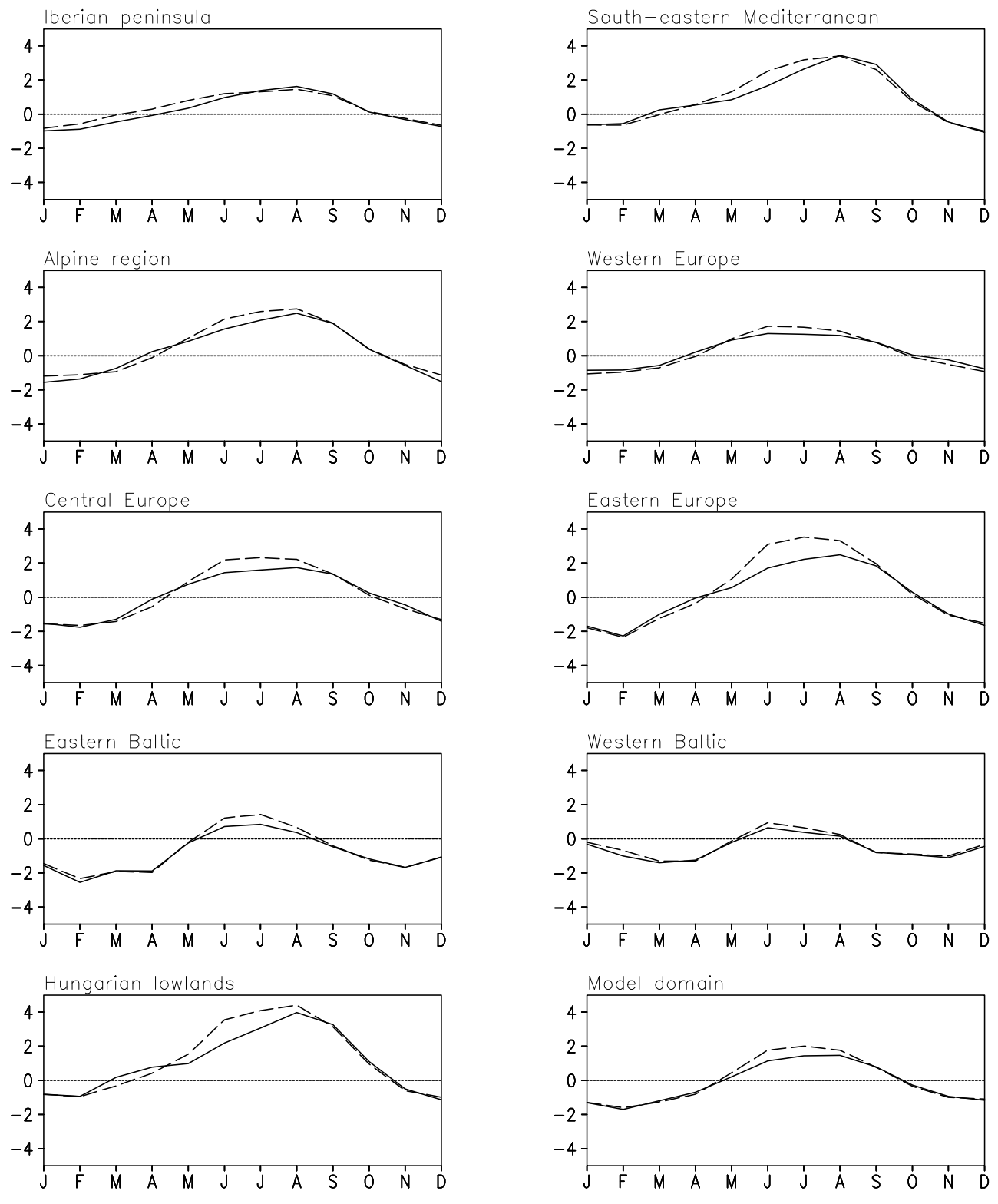

- - constant vegetation

varying vegetation

Figure 13: Mean annual cycles 1979-1993 of differences in $2 \mathrm{~m}$ temperature [K] between VEG-0.5 and CRU and REF-0.5 and CRU, area-averaged over the European subdomains.

$$
\Delta d=\sqrt{\sum_{x y}\left(\frac{\cos (\text { lat }(x, y))}{\sum_{x y} \cos (\text { lat }(x, y))} \cdot \Delta d_{x y}\right)^{2}}
$$

The results are composed in Figure 15. The vegetation effect leads to a significant improvement in $2 \mathrm{~m}$ temperature for all European subdomains except for the Iberian peninsula and the Alpine region. On the Iberian peninsula the mean absolute deviation increases as winter $2 \mathrm{~m}$ temperatures are underestimated. In the Alpine region the mean absolute deviation becomes smaller, but not significantly. Here, the effect of vegetation phenol- ogy is overpowered by the synoptic scale weather conditions. Concerning precipitation, the deviations increase in the Baltic and the Mediterranean area; central and eastern Europe including the Hungarian lowlands show improved results.

\subsection{Summary and conclusion}

This study shows that including the annual cycle of vegetation in the regional climate model REMO does influence the simulated climate in Europe. The more realistic description of vegetation variability strongly affects the water and energy fluxes at the land surface. The raised LAI values and fractional vegetation cover during the growing season directly increase evapotranspiration 

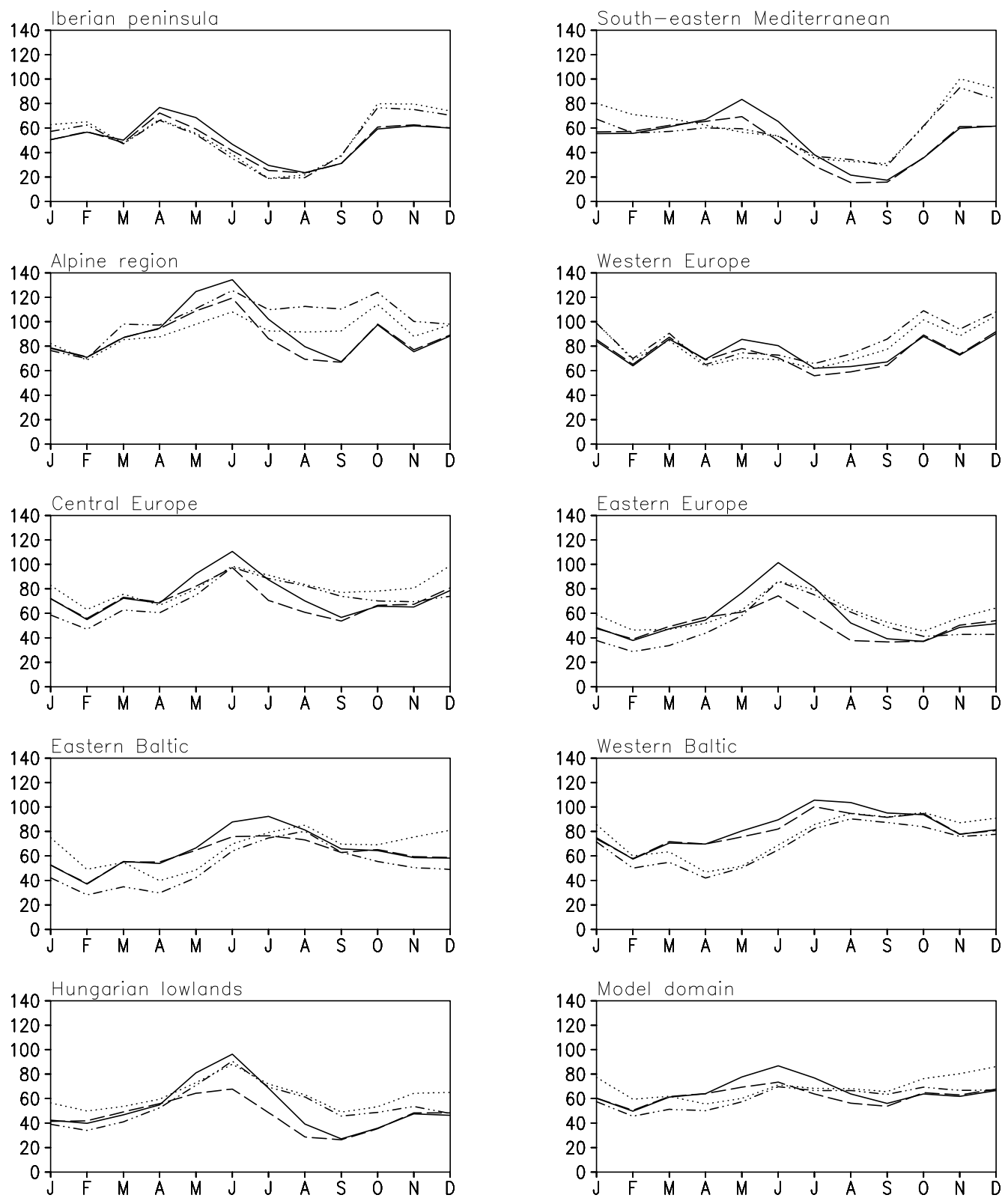

constant veg varying veg

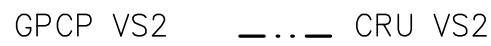

Figure 14: Mean annual cycles 1979-1993 of precipitation [mm/month] for model results of VEG-0.5 and REF-0.5 and observational data of CRU and GPCP, area-averaged over the European subdomains.

and therefore latent heat flux, whereas sensible heat flux is decreased. These changes lead to lower surface temperatures and increased precipitation during the summer season. In all European regions the vegetation effect occurs mainly in the summer season when exchange processes of mass and energy at the land surface are most intensive and strongly controlled by land surface properties. The simulated climate for the winter season is only slightly affected. The spatial analysis of the results show main effects in eastern Europe and the Hungarian lowlands, where the continental climate with intensive vertical exchange processes at the land surface during summer is strongly determined by the altered vegetation parameter values. The simulated climate in the western European regions close to the sea are less affected by the modified vegetation parameterization due to dominating large scale weather conditions. The evaluation of the model simulation at 1/6 degree resolution shows approximately the same vegetation effect on the areaaverage climate. In the horizontal view, the results are more structured and in some regions the spatial precipitation distribution is changed due to the higher resolution. Especially in northern Europe the mesoscale atmospheric circulation is affected by the horizontal model resolution in combination with the modified vegetation treatment. The validation of the modified model version 


Iberian peninsula
\begin{tabular}{|lll|}
\hline & REF-0.5 & VEG-0.5 \\
P:CRU2 & $12.47 / 0.21$ & $13.74 / 0.23$ \\
P:GPCP & $14.03 / 0.24$ & $15.21 / 0.26$ \\
T:CRU2 & $0.96 / 0.014$ & $1.01 / 0.015$ \\
\hline
\end{tabular}

Alpine region

\begin{tabular}{|lll|}
\hline & REF -0.5 & VEG -0.5 \\
P:CRU2 & $34.48 / 0.57$ & $33.77 / 0.59$ \\
P:GPCP & $30.27 / 0.52$ & $31.62 / 0.56$ \\
T:CRU2 & $1.72 / 0.033$ & $1.69 / 0.033$ \\
\hline
\end{tabular}

Central Europe

\begin{tabular}{|lll|}
\hline & REF -0.5 & VEG -0.5 \\
P:CRU2 & $19.26 / 0.23$ & $18.34 / 0.23$ \\
P:GPCP & $20.57 / 0.23$ & $19.87 / 0.23$ \\
T:CRU2 & $1.47 / 0.015$ & $1.26 / 0.014$ \\
\hline
\end{tabular}

Eastern Baltic

\begin{tabular}{|lll|}
\hline & $R E F-0.5$ & $V E G-0.5$ \\
P:CRU2 & $15.47 / 0.14$ & $16.37 / 0.15$ \\
P:GPCP & $14.39 / 0.15$ & $15.02 / 0.15$ \\
T:CRU2 & $1.43 / 0.012$ & $1.33 / 0.013$ \\
\hline
\end{tabular}

Hungarian lowlands

\begin{tabular}{|lll|}
\hline & $R E F-0.5$ & VEG -0.5 \\
P:CRU2 & $15.52 / 0.30$ & $13.77 / 0.25$ \\
P:GPCP & $19.18 / 0.25$ & $18.00 / 0.27$ \\
T:CRU2 & $1.94 / 0.032$ & $1.71 / 0.027$ \\
\hline
\end{tabular}

South-eastern Mediterranean

\begin{tabular}{|lll|} 
& REF -0.5 & VEG -0.5 \\
P:CRU2 & $18.42 / 0.32$ & $19.14 / 0.35$ \\
P:GPCP & $21.12 / 0.34$ & $22.35 / 0.37$ \\
T:CRU2 & $1.64 / 0.028$ & $1.56 / 0.026$ \\
\hline
\end{tabular}

Western Europe

\begin{tabular}{|lll|}
\hline & REF -0.5 & VEG -0.5 \\
P:CRU2 & $19.64 / 0.33$ & $19.37 / 0.34$ \\
P:GPCP & $15.05 / 0.23$ & $15.51 / 0.23$ \\
T:CRU2 & $0.95 / 0.012$ & $0.80 / 0.011$ \\
\hline
\end{tabular}

Eastern Europe

\begin{tabular}{|lll|}
\hline & REF -0.5 & VEG -0.5 \\
P:CRU2 & $14.17 / 0.14$ & $13.03 / 0.15$ \\
P:GPCP & $13.93 / 0.15$ & $12.82 / 0.15$ \\
T:CRU2 & $1.92 / 0.019$ & $1.57 / 0.016$ \\
\hline
\end{tabular}

Western Baltic

\begin{tabular}{|lll|}
\hline & REF -0.5 & VEG -0.5 \\
P:CRU2 & $17.50 / 0.21$ & $18.80 / 0.22$ \\
P:GPCP & $18.10 / 0.24$ & $19.05 / 0.23$ \\
T:CRU2 & $1.21 / 0.014$ & $1.18 / 0.013$ \\
\hline
\end{tabular}

Model domain

\begin{tabular}{|lll|}
\hline & REF -0.5 & VEG -0.5 \\
P:CRU2 & $17.22 / 0.073$ & $17.63 / 0.079$ \\
P:GPCP & $17.45 / 0.074$ & $18.03 / 0.078$ \\
T:CRU2 & $1.49 / 0.006$ & $1.37 / 0.006$ \\
\hline
\end{tabular}

Figure 15: Statistical parameters of the mean annual cycles (1979-1993) of $2 \mathrm{~m}$ temperature and precipitation for VEG-0.5 and REF-0.5 in comparison to CRU and GPCP, area-averaged over the European subdomains. P:CRU2: mean absolute deviation/error in precipitation for REF-0.5 and VEG-0.5 compared to CRU, P:GPCP: mean absolute deviation/error in precipitation for REF-0.5 and VEG-0.5 compared to GPCP, T:CRU2: mean absolute deviation/ error in $2 \mathrm{~m}$ temperature for REF-0.5 and VEG-0.5 compared to CRU.

shows that the simulation results are generally in good agreement with the observations. The statistical analysis of the vegetation effect indicates a significant improvement of the annual $2 \mathrm{~m}$ temperature cycle. Concerning precipitation, central and eastern Europe including the Hungarian lowlands show significantly improved results. But in southern and northern Europe the deviations slightly increase, especially the summer maximum precipitation values are overestimated. This may point to deficiencies in physical parameterizations. Numerous sensitivity experiments with regard to physical parameterizations are performed by the regional climate mod- elling group at MPI-M at this time. In most cases, the effects on precipitation and temperature are of the same order of magnitude as the effect of the altered vegetation parameterization (not shown). The implementation of an annual vegetation cycle improves the representation of vegetation in the model. However, its effect can be superposed by uncertainties due to deficiencies in other model parameterizations as for example in aerosol processes or in the treatment of convective clouds.

The vegetation effect on the simulated climate is outside the internal model variability, because changes do not show spatial or temporal fluctuations on the con- 
sidered scale but go clearly in one direction. In summer, precipitation changes are positive and temperature changes are negative in all European subregions. GIORGI and BI (2000) demonstrate that internal model variability only minimally affects the mean annual cycle of precipitation and temperature. In our case, we have strong effects which can be attributed to the modified vegetation parameters.

Generally, the results of this study are in line with previous global studies on the influence of interannual vegetation variability on the simulated climate (Bounoua et al., 2000, LAWrence and Slingo, 2004a, 2004b). In these experiments larger LAI values also result in cooler and moister near-surface climate. Our regional study focusing on Europe now demonstrates that the climates of the European subregions are affected by the annual vegetation cycle in varying degrees. Related to this work, the study results of LU and SHUTTLEWORTH (2002) are quite interesting. Their NDVI-derived values introduce more spatial heterogeneity to LAI fields and reduce the magnitude of LAI values in comparison to their default model version. In contrast to our study they reduce LAI values in summer, but in spite of this they simulate cooler and wetter climate conditions. They separated the effect of reduced LAI from enhanced heterogeneity which leads to warmer and dryer near-surface summer climate. But reduced LAI in combination with enhanced heterogeneity lead to cooler and wetter climate conditions. Thus, their conclusion is that the introduction of increased spatial heterogeneity is the primary cause of the cooler and wetter summer climate. In future REMO model studies it would be quite interesting to perform a similar sensitivity study with NDVI-derived LAI fields.

\section{Acknowledgements}

This research was supported by the Federal Ministry of Education and Research (BMBF, project number 01LD0026) within the German Climate Research Program DEKLIM-IVECC project ("Impact of vegetation on regional climate and climate change simulations") contributing to the consortium "Quantification of uncertainties in regional climate and climate change studies" QUIRCS. We are very grateful to our colleagues of the MPI-M for their good cooperation, especially to Stefan HAGEMANN for the new global dataset of land surface parameters, to Ralf PODZUN for technical model support and to Holger GOETTEL for helpful discussions. Special thanks to the reviewers for their help in improving the manuscript.

\section{References}

Avissar, R., M.M. Verstraete, 1990: The representation of continental surface processes in atmospheric models. - Rev. Geophys. 28, 35-52.
BONAN G.B., 1997: Effects of land use on the climate of the United States. - Climatic Change 37, 449-486.

Bougeault, P., 1983: A non-reactive upper boundary condition for limited-height hydrostatic models. - Mon. Wea. Rev. 111, 420-429.

Bounoua L., G.J. Collatz, S.O. Los, P.J. Sellers, D.A. DAZlich, C.J. TuCKer, D.A. RANDAll, 2000: Sensitivity of climate to changes in NDVI. - J. Climate 13, 2277-2292.

Chase T.N., R.A. Pielke, T.G.F. Kittel, R. Nemani, S.W. RUNNING, 2000: Simulated impacts of historical land cover changes on global climate in northern winter. - Climate Dyn. 16, 93-105.

Collins, D.C., R. Avissar, 1994: An evaluation with the Fourier Amplitude Sensitivity Test (FAST) of which land surface parameters are of greatest importance in atmospheric modelling. - J. Climate 7, 681.

DAVIES, H.C., 1976: A lateral boundary formulation for multi-level prediction models. - Quart. J. Roy. Meteor. Soc. 102, 405-418.

DKRZ, 1993: Deutsches Klimarechenzentrum: The ECHAM-3 general circulation model. - DKRZ Techn. Rep. 6, Hamburg.

DüMEnIL, L., E. TODINI, 1992: A rainfall-runoff scheme for use in the Hamburg climate model. - In: J.P. O'KANE (Ed.): Advances in Theoretical Hydrology. A Tribute to James DoogE. European Geophysical Society Series on Hydrological Sciences, 1, Elsevier Press, Amsterdam, 129157.

EIDENSHink, J.C., J.L. FAundeEn, 1994: The $1 \mathrm{~km}$ AVHRR global land data set: First stages in implementation. - Int. J. Remote Sens. 15, 3443-3462.

GoIRGi, F., X. BI, 2000: A study of internal variability of a regional climate model. - J. Geophys. Res. 105, 2950329521.

HaGEMAnN, S., 2002: An improved land surface parameter dataset for global and regional climate models. - Rep. 336, Max-Planck-Institute for Meteorology, Hamburg.

Hagemann, S., M. Botzet, L. Dümenil, B. MachenHAUER, 1999: Derivation of global GCM boundary conditions from $1 \mathrm{~km}$ land use satellite data. - Rep. 289, MaxPlanck-Institute for Meteorology, Hamburg.

Hagemann, S., M. Botzet, B. Machenhauer, 2001: The summer drying problem over south-eastern Europe: Sensitivity of the limited area model HIRHAM4 to improvements in physical parameterizations and resolution. Phys. and Chem. of the Earth B 26(5-6), 391-396.

HENDERSON-SELlers, A., 1993: A factorial assessment of the sensitivity of the BATS land-surface parameterization scheme. - J. Climate 6, 227-247.

Huffman, G.J., R.F. Adler, A. Arkin, A. Chang, R. Ferraro, A. Gruber, J. Janowiak, R.J. Joyce, A. McNab, B. Rudolf, U. SchneIder, P. XIE, 1997: The Global Precipitation Climatology Project (GPCP) combined precipitation data set. - Bull. Amer. Meteor. Soc. 78 $5-20$.

JACOB, D., 2001: A note to the simulation of the annual and interannual variability of the water budget over the Baltic Sea drainage basin. - Meteor. Atmos. Phys. 77, 1-4, 6173. 
JACOB, D., R. PoDZun, 1997: Sensitivity studies with the regional climate model REMO. - Meteor. Atmos. Phys. 63, 119-129.

Ja $\overline{C O B}$, D., U. Andrae, G. Elgered, C. Fortelius, P.L. GRAHAM, S.D. JACKSON, U. Karstens, C. KoEPKEn, R. Lindau, R. PODZun, B. Rockel, F. Rubel, H.B. SASS, R.N.D. SMITH, B.J.J.M. VAN DEN HURK, $\mathrm{X}$. YANG, 2001: A comprehensive model inter-comparison study investigating the water budget during the BALTEXPIDCAP period. - Meteor. Atmos. Phys. 77, 19-43.

LAWrenCE, D.M., J.M. SLINGO, 2004a: An annual cycle of vegetation in a GCM. Part I: Implementation and impact on evaporation. - Climate Dyn. 22, 87-105.

- , - 2004b: An annual cycle of vegetation in a GCM. Part II: Global impacts on climate and hydrology. - Climate Dyn. 22, 107-122.

LOUIS, J.-F., 1979: A parametric model of vertical eddy fluxes in the atmosphere. - Bound.-Layer Meteor. 17, 187202.

LU, L., W.J. ShUtTLEWORTH, 2002: Incorporating NDVIderived LAI into the climate version of RAMS and its impact on regional climate. - J. Hydrometeor. 3, 347-362.

MAJEWSKI, D., 1991: The Europa-Modell of the Deutscher Wetterdienst. - ECMWF Seminar on Numerical Methods in Atmospheric Models 2, 147-191.

MinTZ, Y., 1984: The sensitivity of numerically simulated climates to land-surface boundary conditions. - In: Houghton, J.T. (Ed.), The Global Climate. Cambridge. Uni. Press, 79-105.

Mitchell, T.D., T.R. CARTer, P.D. Jones, M. Hulme, M. NEW, 2004: A comprehensive set of high-resolution grids of monthly climate for Europe and the globe: The observed record (1901-2000) and 16 scenarios (2001-2100). - Working Pap. 55, Tyndall Cent., Norwich, U. K.

New, M., M. Hulme, P. Jones, 2000: Representing twentieth-century space-time climate variability. Part II: Development of 1901-96 monthly grids of terrestrial surface climate. - J. Climate 13, 2217-2238.

OLSON, J.S., 1994a: Global ecosystem framework: definitions. - USGS EROS Data Centre Internal Report, Sioux Falls, SD, $37 \mathrm{pp}$.

—, 1994b: Global ecosystem framework: translation strategy. - USGS EROS Data Centre Internal Report, Sioux Falls, SD., 39 pp.

Pielke, R.A., T.J. Lee, J.H. Copeland, J.L. EAStMAN, C.L. ZIEGLER, C.A. FInLEY, 1997: Use of USGSprovided data to improve weather and climate simulations. - Ecological Appl. 7, 3-21.

Pielke R.A., R. AVisSAR, M. RaUPaCh, A.J. Dolman, X. Zeng, A.S. DEnNing, 1998: Interactions between the atmosphere and terrestrial ecosystems: influence on weather and climate. - Global Change Biology 4, 461-475.

RECHID, D., 2001: Untersuchung zur Parameterisierung von Landoberflächen im regionalen Klimamodell REMO. Diploma Thesis, Max-Planck-Institute for Meteorology, Hamburg.
Rodriguez-CAmino, E., R. Avissar, 1998: Comparison of three land surface schemes with the Fourier Amplitude Sensitivity Test (FAST). - Tellus 50A, 313-332.

Roeckner, E., K. Arpe, L. Bengtsson, M. Christoph, M. Claussen, L. DÜmenil, M. Esch, M. Giorgetta, U. Schlese, U. SChUlzWEIDA, 1996: The atmospheric general circulation model ECHAM-4: Model description and simulation of present-day climate. - Report 218, Max-Planck-Institute for Meteorology, Hamburg.

RowntreE, P.R., 1991: Atmospheric parameterization schemes for evaporation over land: basic concepts and climate modelling aspects. - In: SchMUgGe, T. J. ANDRE (Eds.): Land Surface Evaporation - Measurement and $\mathrm{Pa}-$ rameterization, Springer Verlag, 5-29.

SELLERS, P.J., 1991: Modelling and observing land-surfaceatmosphere interactions on large scales. - Surveys in Geophys. 12, 85-114.

Sellers, P.J., Y. MintZ, Y.C. Sud, A. DAlCher, 1986: A simple biosphere ( $\mathrm{SiB}$ ) for use within general circulation models. - J. Atmos. Sci. 43, 505-531.

SEMmler, T., D. JACOB, K.H. SCHLÜNZEN, R. PODZun, 2004: Influence of sea ice treatment in a regional climate model on boundary layer values in the Fram Strait region. - Mon. Wea. Rev. 132, 985-999.

Seneviratne, S.I., J.S. Pal, E.A.B. Eltahir, C. SCHÄR, 2002: Summer dryness in a warmer climate: A process study with a regional climate model. - Climate Dyn. 20, 69-85.

ShuKlA, J., Y. Mintz, 1982: Influence of land surface evapotranspiration on the earth's climate. - Science $\mathbf{2 1 5}$, 1498-1501.

Simmons, A.J., D.M. BurRidge, 1981: An energy and angular-momentum conserving vertical finite-difference scheme and hybrid vertical coordinate. - Mon. Wea. Rev. 109, 758-766.

Stohlgreen T.J., T.N. Chase, R.A. Pielke, S. TimoTHY, G.F. KiTTEL, J.S. BARON, 1998: Evidence that local land use practices influence regional climate, vegetation, and stream flow patterns in adjacent natural areas. - Global Change Biology 4, 495-504.

SUD Y.C., J. SHUKLA, Y. MINTZ, 1988: Influence of land surface roughness on atmospheric circulation and precipitation: A sensitivity study with a general circulation model. - J. Appl. Meteor. 27, 1036-1054.

Sud, Y.C., P.J. Sellers, Y. Mintz, M.D. ChOU, G.K. WAKER, W.E. SMITH, 1990: Influence of the biosphere on the global circulation and hydrologic cycle - a GCM simulation experiment. - Agric. Forest Meteor. 52, 133-180.

Warrilow, D.A., A.B. SAngster, A. Slingo, 1986: Modelling of land surface processes and their influence on European climate. - Met O 20 Technical Note DCTN 38 , Meteorological Office, Bracknell, UK. 